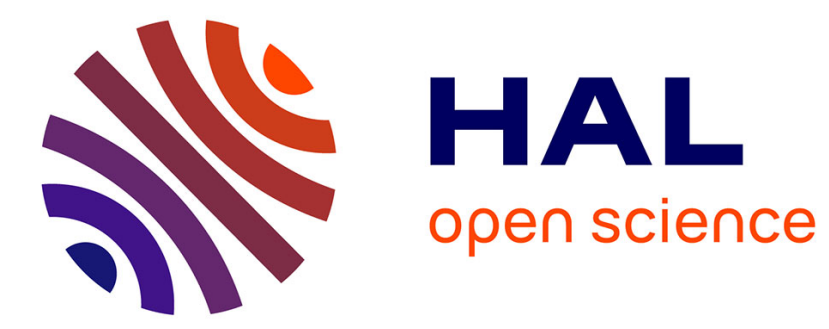

\title{
Optimal nuclear liability insurance
}

Alexis Louaas, Pierre Picard

\section{To cite this version:}

Alexis Louaas, Pierre Picard. Optimal nuclear liability insurance. 2019. hal-01996648

\section{HAL Id: hal-01996648 \\ https://hal.science/hal-01996648}

Preprint submitted on 28 Jan 2019

HAL is a multi-disciplinary open access archive for the deposit and dissemination of scientific research documents, whether they are published or not. The documents may come from teaching and research institutions in France or abroad, or from public or private research centers.
L'archive ouverte pluridisciplinaire HAL, est destinée au dépôt et à la diffusion de documents scientifiques de niveau recherche, publiés ou non, émanant des établissements d'enseignement et de recherche français ou étrangers, des laboratoires publics ou privés. 


\title{
Optimal nuclear liability insurance
}

\author{
Alexis Louaas* and Pierre Picard ${ }^{\dagger}$
}

January 15, 2019

\begin{abstract}
We analyze the insurance of nuclear liability risk, from theoretical and applied standpoints. Firstly, we characterize the optimal insurance scheme for a low-probability industrial accident, such as a nuclear catastrophe, in a model of collective risk-sharing. Using catastrophe bond data, we then evaluate the cost of capital sustaining such an insurance mechanism. Finally, we characterize the individual lotteries associated with the risk of a nuclear accident in France, and we estimate the optimal coverage. We conclude that the corporate liability limit currently in force is likely to be inferior to the socially optimal level.
\end{abstract}

${ }^{*}$ CREST-Ecole Polytechnique, France. E-mail : alexis.louaas@polytechnique.edu

${ }^{\dagger}$ CREST-Ecole Polytechnique, France. E-mail : pierre.picard@polytechnique.edu 


\section{Introduction}

Low probability - high severity disaster risks, like nuclear catastrophes, 1 create enormous difficulties to governments looking for an optimal financial coverage of losses incurred by their citizens. The Fukushima disaster that occurred in March 2011 for instance, led the Japanese authorities to evacuate 150000 people up to 20 kilometers around the damaged power plant. Solely for the purpose of decontamination, indemnification and decommissioning, the Japanese government expects a cost of 177 billion euros.2

Even-though a large fraction of this cost is diffuse and difficult to handle through liability law, the severity of catastrophes such as Fukushima (both in terms of number of victims and in terms of average loss), suggests that large welfare gains can be expected from a well-designed insurance scheme. However, as highlighted by Jaffee and Russel (1997), Froot (2001), Niehaus (2002) and Zanjani (2002), the systemic aspect of such risks makes it difficult to provide insurance at reasonable prices, since costly capital must be collateralized for the event of a catastrophe. A socially optimal insurance scheme therefore results from the trade-off between a high demand for coverage, created by the severity of potential accidents and the cost incurred by the financial institutions to which such risks may be transferred. This article focuses attention more specifically on the case of nuclear liability insurance $\mathrm{H}^{3}$

In most countries, nuclear operators have a limited liability for the damages they may cause. In western Europe, the conventions of Paris (1960) and Brussels (1963) set a lower bound on the liability limit of the nuclear operators. In order to cover their liability, operators consequently take out third-party liability insurance. Currently, the minimal corporate liability,

\footnotetext{
${ }^{1}$ Large scale nuclear accidents are extreme examples of low probability - high severity risks. Since 1952 and the beginnings of civil nuclear programs, only a handful of severe nuclear accidents have been registered in the world. Fukushima (2011) was ranked at the highest severity level on the International Nuclear Events Scale (INES). INES, engineered by the International Atomic Energy Agency, ranges from 1 for mere anomalies to 7 for major accidents. As of today, only Chernobyl (1986) and Fukushima (2011) were ranked at the highest level 7. The accident of Kyshtym (1957), in Russia was ranked at level 6 and Windscale Pile (1957) in Canada, Chalk River (1952) in Great-Britain, Three-Mile Island (1979) in the US have been ranked at level 5. The historical frequency of nuclear accidents is estimated at $0.07 \%$ per year and per reactor (Rangel and Levêque (2014)).

2 Www.bbc.com/news/world-asia-38131248.

${ }^{3}$ Catastrophe risks may entail macroeconomic effects on asset prices (Rietz (1988), Barro (2009), Gabaix (2012) and Farhi and Gabaix (2015)), business cycles (Gourio (2012)), and welfare (Weitzman (2009)). For our part, we adopt a more normative perspective and we focus on the components of disaster risk that can be covered through liability law. The other losses may be considered as a, potentially large, uninsurable correlated background risk.
} 
imposed by the 2004 protocol to amend the Paris Convention, is set at 700 million euros per accident. In France, the operator's liability is set at this new 700 million euros lower bound, which contrasts with Germany, that has adopted a 2.5 billion euros liability. In other countries such as Japan and the United-States, nuclear liability is organized by national legislation. For instance, the Price-Anderson Act provides for an overall coverage higher than 10 billion in the United-States 4

Our objective in this paper is twofold. Firstly, we develop a theoretical analysis of optimal liability insurance for a low-probability industrial catastrophe. Secondly, we use this theoretical setting to characterize an optimal nuclear liability insurance scheme in France. Our main conclusion is that the current liability limit is likely to be inferior to the socially optimal level.

Our theoretical framework extends the canonical models of insurance design (Mossin (1968) and Raviv (1979)) to take into account the specificities of nuclear catastrophe risk. More precisely, we consider the risk of a large scale industrial catastrophe, such as a nuclear accident, that may affect the entire population of a country. Should an accident occur, the firm has to indemnify the victims according to liability law, and it purchases insurance to prevent any insolvency. When the accident probability is very small, the optimal insurance coverage is a straight deductible indemnity schedule, common to all agents. From a theoretical perspective, this result extends Arrow's (1963) theorem on the optimality of deductibles for individual risks, to the case of a socially optimal disaster insurance scheme. From a practical perspective, it enables us to construct such a scheme.

There are three main building blocks in this construct: firstly, the assessment of damages that may be caused by a nuclear accident, secondly, the modelling of risk preferences, and finally, the cost of the capital needed to sustain the insurance coverage of a non-diversifiable risk such as the nuclear accident risk.

With regard to the two first points, our methodology builds on Eeckhoudt et al. (2000), who try to evaluate the social cost of nuclear risk. Postulating a Constant Relative Risk Aversion (CRRA) utility function, they conclude that the cost estimate is strongly sensitive to the level of risk aversion. This lack of robustness of the CRRA specification for cost-benefit analysis in the presence

\footnotetext{
${ }^{4}$ These figures suggest that, compared with the losses that a nuclear catastrophe may cause, the current scope of legal nuclear liability is rather narrow. This tenuity reflects the limits of liability mechanisms to compensate victims which is due, among other things, to the difficulty to assess individual losses and their causes. For example, extending the validity of health-related claims from 10 to 30 years triggered much protest among major actors of the insurance industry, and endless discussions in the countries that are signatories of the 2004 Protocol to amend the Paris convention.
} 
of catastrophe risk is also present in Weitzman's (2009) dismal theorem. For our part, we will use the more general Harmonic Absolute Risk Aversion (HARA) functions, that have been shown to be more robust to tail risk (Millner (2013), Ikefuji et al. (2015)).

Concerning the third building block, measuring the cost of capital leads us to consider the Alternative Risk Transfer instruments, surveyed in Barrieu and Cummins (2013). We elaborate on Lane (2000), Major and Kreps (2002), Lane and Mahul (2008), and Braun (2015) to build a model of catastrophe bond pricing $5^{5}$ Our model differs from existing ones along two dimensions: it allows for realistic price estimates for low-probability risks and for an increasing marginal cost of capital. Our estimates are consistent with previous studies, and our model's performance compares favorably to existing models on the probability interval for which observations are available, with much more reasonable price predictions for low-probability events.

Using these three building blocks together, and considering the case of France, allows us to evaluate the socially optimal liability insurance scheme for nuclear risk. Our simulations suggest that the French nuclear liability law should be more ambitious than it currently is, even after the 2004 revision of the Paris Convention 6

The paper is organized as follows. Section 2 characterizes the optimal corporate liability insurance when a large scale industrial accident may affect the whole population of a country and the insurance pricing rule is taken as given. Section 3 builds and estimates the model of capital cost that sustains the insurance scheme. Section 4 builds the individual lotteries of individuals who face a nuclear disaster risk. Section 5 simulates the corresponding optimal coverage. Finally, Section 6 concludes and Section 7 is an appendix that contains proofs, tables and additional robustness checks.

\footnotetext{
${ }^{5}$ Perez and Carayannopoulos (2015), have shown that cat bond returns feature little correlation with other asset prices. This suggests that cat bonds could be used to secure capital at reasonable prices, hence allowing for higher levels of coverage against catastrophes.

${ }^{6}$ Schneider and Zweifel (2004) have used a survey approach to evaluate the willingness to pay for risk reduction and to infer the welfare gain that would result from an increase in corporate nuclear liability in Switzerland. Although their methodology is deeply different from ours, they obtain comparable estimates of the optimal level of coverage.
} 


\section{Optimal catastrophic risk coverage for a population}

\subsection{Catastrophic risk with corporate liability insur- ance}

With the case of nuclear accident risk in mind, we consider a population of individuals who face the risk of a catastrophic event (called "the accident") caused by a firm. Such an accident may affect the individuals differently, according to their risk exposure and also to their good or bad luck. The population is represented by a continuum of individuals with unit mass. It is composed of $n$ groups or types indexed by $i=1, \ldots, n$, and a proportion $\alpha_{i}$ of the population belongs to group $i$, with $\alpha_{1}+\alpha_{2}+\ldots+\alpha_{n}=1$. In the case of a nuclear accident caused by a given reactor, the groups correspond to various locations that may be more or less distant from the nuclear power plant. The accident occurs with probability $\pi$. In the case of an accident, a proportion $q_{i} \in[0,1]$ of type $i$ individuals suffers damage, with financial damage $\widetilde{x}_{i}$ for each individual in this subgroup of victims. $\widetilde{x}_{i}$ is a random variable, whose realization is denoted $x_{i}$, and which is distributed over the interval $\left[0, \bar{x}_{i}\right]$ with c.d.f. $F_{i}\left(x_{i}\right)$ and density $f_{i}\left(x_{i}\right)=F_{i}^{\prime}\left(x_{i}\right)$. The random variables $\widetilde{x}_{i}$ are independently distributed among type $i$ individuals. Thus, an accident induces a total cost per individual equal to

$$
\sum_{i=1}^{n} \alpha_{i} q_{i}\left[\int_{0}^{\bar{x}_{i}} x_{i} f_{i}\left(x_{i}\right) d x_{i}\right]=\sum_{i=1}^{n} \alpha_{i} q_{i} \mathbb{E} \widetilde{x}_{i},
$$

Under our assumptions, this total cost is given, but the distribution of loss between members of each group is random. This provides a simple correlation structure of losses. There is one single accident risk, which is thus nondiversifiable. In the case of an accident, the losses per individual are equal to $q_{i} \mathbb{E} \widetilde{x}_{i}$ in each group $i=1, \ldots, n$, and thus aggregate losses per individuals $\widetilde{L}$ are equal to $\sum_{i=1}^{n} \alpha_{i} q_{i} \mathbb{E} \widetilde{x}_{i}$ with probability $\pi$, and $\widetilde{L}=0$ with probability $1-\pi$. Hence, $\widetilde{L}$ has expected value $\mathbb{E}(\widetilde{L})=\pi \sum_{i=1}^{n} \alpha_{i} q_{i} \mathbb{E} \widetilde{x}_{i}$ and standard deviation $\sigma(\widetilde{L})=\sqrt{\pi(1-\pi)} \sum_{i=1}^{n} \alpha_{i} q_{i} \mathbb{E} \widetilde{x}_{i}$, and its coefficient of variation is $C V(\widetilde{L})=\sigma(\widetilde{L}) / \mathbb{E}(\widetilde{L})=\sqrt{(1-\pi) / \pi} . C V(\widetilde{L})$ goes to infinity when $\pi$ goes to zero, which reflects the high volatility of the accident risk when its probability is small.

Each type $i$ individual is covered by an insurance contract that specifies an indemnity $I_{i}\left(x_{i}\right) \geq 0$ for all $x_{i}$ in $\left[0, \bar{x}_{i}\right]$. This insurance coverage is taken out by the firm at price $P$. The firm has to indemnify the victims according to the legal rule $I_{i}\left(x_{i}\right)$ and also - in order to prevent any bankruptcy risk 
- it has to purchase insurance to cover its liability. Thus, $I_{i}\left(x_{i}\right)$ is at the same time the payment by the firm to type $i$ individuals and the transfer from the insurer to the firm. The firm pays a premium $P$ per individual, and this premium is passed on to the prices of the firm's product (say, on to the consumers' electricity bills). We assume that all consumers purchase the same quantity of the firm's products, and thus it is as if the insurance premium were paid by the individuals themselves.

Assume that the insurer allocates an amount of capital per individual $K$ in order to pay indemnities, should an accident occur. The usual mutualization mechanism cannot be effective in the case of a common exposure to a single source of risk, and some alternative risk transfer is required. A simple approach (at least from a conceptual standpoint) consists in the insurer issuing a cat bond with par value $K$. The cat bond will pay some return (a spread above the risk-free rate of return), and will be reimbursed to investors only if no accident occurs. Otherwise, the cat bond will default, and its proceeds will be used to cover the claims for victims' compensation.7

We know from the law of large numbers that the average indemnity paid to type $i$ victims in the case of an accident is

$$
\int_{0}^{\bar{x}_{i}} I_{i}\left(x_{i}\right) f_{i}\left(x_{i}\right) d x_{i}
$$

and thus the total indemnity payment can be financed if

$$
K=(1+\lambda) \sum_{i=1}^{n} \alpha_{i} q_{i} \int_{0}^{\bar{x}_{i}} I_{i}\left(x_{i}\right) f_{i}\left(x_{i}\right) d x_{i}
$$

where $\lambda$ is a loading factor that represents the claim handling costs that the insurer faces beyond the indemnification costs. This cost of capital is covered by the premiums raised by the insurer, so we have

$$
P=c(\pi, K)
$$

where $c(\pi, K)$ is the cost of capital function, more precisely defined hereafter, and such that $c(\pi, K)$ is assumed twice continuously differentiable, $c_{K}^{\prime}>0$,

\footnotetext{
${ }^{7}$ In practice, a Special Purpose Vehicle (SPV) is created by the sponsor (here, the insurer) as a legal entity able to host the cat bond. This SPV acts as an insurer or reinsurer with respect to the sponsor. It issues the bond, delivered to the investors in exchange for the principal payment, which entitles them to a regular coupon. Upon the occurrence of a contractually defined event, called the trigger, the bond defaults and the sponsor gets to keep the principal. Cat bonds are used by insurers and reinsurers to hedge against large losses among their portfolios of insured people, and by large corporations to cover catastrophic events.
} 
$c \rightarrow c(0, K) \geq 0$ and $c_{K}^{\prime} \rightarrow 0$ when $\pi \rightarrow 0, c_{\pi}^{\prime}>0, c_{K^{2}}^{\prime \prime} \geq 0$ and $c_{\pi K}^{\prime \prime} \geq 1.8$

All individuals have the same initial wealth $w$ and the same risk preferences represented by utility function $u$, with $u^{\prime}>0, u^{\prime \prime}<0$. Let $w_{1}$ and $w_{2 i}\left(x_{i}\right)$ be the wealth of a type $i$ individual if he is not affected by an accident (which occurs with probability $1-\pi q_{i}$ ), and if he is affected with loss $x_{i}$ (which occurs with probability $\pi q_{i}$ and conditional loss density $f_{i}\left(x_{i}\right)$ ), respectively. We have

$$
\begin{aligned}
w_{1} & =w-P, \\
w_{2 i}\left(x_{i}\right) & =w-P-x_{i}+I_{i}\left(x_{i}\right) .
\end{aligned}
$$

Let $C_{i}$ be the certainty equivalent loss of type $i$ individuals. The set of feasible allocations $\left\{w_{1}, w_{21}\left(x_{1}\right), \ldots, w_{2 n}\left(x_{n}\right), C_{1}, \ldots, C_{n}, K\right\}$ is defined by

$$
\begin{gathered}
u\left(w-C_{i}\right)=\left(1-\pi q_{i}\right) u\left(w_{1}\right)+\pi q_{i} \int_{0}^{\overline{x_{i}}} u\left(w_{2 i}\left(x_{i}\right)\right) f_{i}\left(x_{i}\right) d x_{i}, \\
w_{2 i}\left(x_{i}\right)-w_{1}+x_{i} \geq 0 \text { for all } i=1, \ldots, n, \\
K=(1+\lambda) \sum_{i=1}^{n} \alpha_{i} q_{i} \int_{0}^{\bar{x}_{i}} I_{i}\left(x_{i}\right) f\left(x_{i}\right) d x_{i}, \\
w_{1}=w-c(\pi, K) .
\end{gathered}
$$

Equation (1) defines $C_{i}$ and equation (2) corresponds to the sign constraint $I_{i}\left(x_{i}\right) \geq 0$. (3) defines the capital required to pay indemnities, and (4) follows from $w_{1}=w-P$ and $P=c(\pi, K)$.

\subsection{Optimal contract}

We consider a utilitarian regulator that designs the risk coverage mechanism in order to minimize the social cost of an accident, which is the weighted sum of certainty equivalent to individuals' losses. The corresponding optimization program is also a way of characterizing the Pareto optimal allocations when ex-ante transfers between groups are possible.9 This may be written as minimizing

$$
\sum_{i=1}^{n} \alpha_{i} C_{i}
$$

\footnotetext{
${ }^{8}$ If capital is levied through a cat bond, then $c(\pi, K) / K$ is the spread over LIBOR, i.e. the compensation per euro required by investors for running the risk of losing their capital with probability $\pi$. Under a zero risk-free interest rate, a risk neutral investor would require $c(\pi, K)=\pi K$ to accept this risk. Note that we may have $c(0, K)>0$ if levying capital $K$ induces fixed costs. See Section 3 for further developments.

${ }^{9}$ See Proposition 2 in the appendix for details.
} 
with respect to $\left\{w_{1}, w_{21}\left(x_{1}\right), \ldots, w_{2 n}\left(x_{n}\right) ; C_{1}, C_{2}, \ldots, C_{n}, K\right\}$, subject to conditions (1), (2), (3) and (4). Proposition 1 characterizes the optimal solution of this problem when $\pi$ goes to 0 and $K>0$

Proposition 1 When $\pi$ goes to zero with $K>0$, all the optimal indemnity schedules $I_{i}\left(x_{i}\right)$ converge toward a common straight deductible indemnity schedule $I^{*}\left(x_{i}\right)=\max \left(x_{i}-d^{*}, 0\right)$ and $K$ converges toward $K^{*}$ defined by

$$
\begin{gathered}
u^{\prime}\left(w-d^{*}\right)=(1+\lambda) u^{\prime}\left(w-c_{0}^{*}\right) c_{\pi K}^{\prime \prime}\left(0, K^{*}\right), \\
K^{*}=(1+\lambda) \sum_{i=1}^{n} \alpha_{i} q_{i}\left[\int_{d^{*}}^{\bar{x}_{i}}\left(x_{i}-d^{*}\right) f_{i}\left(x_{i}\right) d x_{i}\right],
\end{gathered}
$$

where $c_{0}^{*}=c\left(0, K^{*}\right)$.

Proposition 1 shows that the optimal indemnity schedule for small $\pi$ involves full coverage of the victims above a straight deductible $d^{*}$ (the same for all individuals whatever their type). This amounts to saying that the victims should be ranked in order of priority on the basis of their losses: the victims with loss $x_{i}$ should receive an indemnity only if the victims with loss $x_{i}^{\prime}$ larger than $x_{i}$ receive at least $x_{i}^{\prime}-x_{i}$. This simple characterization of optimal indemnification will be used in the simulation conducted in Section 5 . We may derive comparative statics properties for the asymptotic deductible $d^{*}$. In particular, it is increasing in $\lambda$ and, under $D A R A$ preferences, it is increasing in wealth.

More importantly, Proposition 1 shows how $d^{*}$ and $K^{*}$ are affected by the cost of capital. If the investors were risk neutral, we would have $c(\pi, K)=$ $\pi K$, i.e. the cost of capital would just be equal to the risk premium that compensates for the expected loss due to the default. We would have $c_{\pi K}^{\prime \prime}(\pi, K)=$ 1 and, in such a case, the cost of capital would not affect the optimal indemnity schedule.

However, as we will see in more detail in Section 3 with the example of the cat bond market for low-probability triggers, because of the aversion of investors towards risk, or for other reasons, it is much more realistic to keep the cost of capital in a more general form $c(\pi, K)$. In that case the

\footnotetext{
${ }^{10}$ When $\pi$ goes to zero, the certainty equivalents $C_{i}$ also tend to zero. However, they may remain significant (for example in percentage of expected loss) for $\pi$ small but positive. Louaas and Picard (2018) show that this is the case under Decreasing Absolute Risk Aversion if the index of absolute risk aversion is large in the loss state. The simulations reported in Section 5 illustrate this result.
} 
cost of capital does affect the optimal indemnity schedule as highlighted in Proposition $1{ }^{11}$

The optimality of straight deductible contracts was first established by Arrow (1963) ${ }^{12}$ in a different perspective. While Arrow studied individual insurance decisions, we are concerned with the design of a socially optimal insurance scheme, where an entire population is exposed to a common source of risk and the cost of insurance is uniformly spread among inhabitants. This implies that there is cross-subsidization from the less exposed to the more exposed individuals. In Arrow (1963), both the optimal price and deductible depend on the risk profile of a particular agent. In contrast, Proposition 1 indicates that all indemnity schedules converge toward a single coverage rule, characterized by $d^{*}, K^{*}$, and the associated premium $P^{*}=c_{0}^{*}$. The fact that the deductible does not depend on type $i$ is true only asymptotically when $\pi \longrightarrow 0$. Otherwise, the optimal indemnity schedule would involve typedependent deductibles $d_{i}$, with $I_{i}\left(x_{i}\right)=\max \left\{x_{i}-d_{i}, 0\right\}$. This is because lower deductibles would allow the regulator to transfer wealth from less to more risky types (say, from the groups with $q_{i}$ low to the groups with $q_{i}$ high if the conditional distribution of losses $F_{i}\left(x_{i}\right)$ is the same for all groups). For low-probability risks, this compensatory effect vanishes as $\pi$ goes to 0 .

\section{The cost of capital}

Financial innovations have been developed during the last two decades in order to transfer large scale catastrophic risks to financial markets 13 Focusing attention on the cat bond market, we may write $c(\pi, K)=s(\pi, K) K$, where

\footnotetext{
${ }^{11}$ Note that $c_{\pi, K}^{\prime \prime}\left(0, K^{*}\right)=\lim _{\pi \rightarrow 0}(1-\pi) c_{K}^{\prime}\left(\pi, K^{*}\right) / \pi$ from L'hôpital's rule. Then, Proposition 1 yields, for $\pi$ small enough

$$
\frac{\pi u^{\prime}\left(w-d^{*}\right)}{(1-\pi) u^{\prime}\left(w-c_{0}^{*}\right)} \approx(1+\lambda) c_{K}^{\prime}\left(\pi, K^{*}\right) .
$$

The left-hand side of this equality is the individual's marginal rate of substitution between the states where he receives an indemnity after an accident and where no accident occurs, respectively. The right-hand side is the marginal cost of capital needed to sustain the insurance coverage, inflated by the loading factor $\lambda$. Hence, the first condition in Proposition 1 may be interpreted as the equality between marginal willingness to pay and marginal cost of coverage. The second equation is just a rewriting of equation (3) for the indemnity schedule $I^{*}\left(x_{i}\right)$.

${ }^{12}$ This result has been generalized in many directions. Gollier and Schlesinger (1996) for example, demonstrate that a deductible second-degree stochastically dominates any other feasible insurance policy. For more on the robustness of Arrow's optimality result, see Gollier (2013).

${ }^{13}$ See Barrieu and Cummins (2013).
} 
$s(\pi, K)$ denotes the spread over LIBOR for a cat bond.

The empirical literature has developed a number of cat bond pricing models, of which we present four examples in Appendix 7.7. However, these models suffer from a lack of theoretical foundations and they predict unrealistically high spreads for cat bonds with very low-probability triggers. ${ }^{14}$ We therefore develop in Appendix 7.2 a simple one factor cat bond pricing model with the following features. The representative investor is assumed to be risk averse. In addition to the compensation for his expected loss, he therefore demands a premium for the systemic component of the risk that is correlated with his own wealth. He also requires a compensation for the underwriting and verification costs induced by the cat bond transaction. Our predictions for low-probability cat bonds will therefore lie between two extremes. Spreads will be lower than those predicted by the existing models, presented in Appendix 7.7, but higher than those predicted in a model with risk neutral investors and no fixed cost.

Our pricing equation is as follows

$$
s=\pi(1+\mu) \mathbb{E}(\tilde{y})+\eta \kappa(1+\mu) \pi\left[\mathbb{E}\left(\tilde{y}^{2}\right)-\pi(\mathbb{E} \tilde{y})^{2}\right] K+\frac{D}{K},
$$

where $\tilde{y}$ is the fraction of the cat bond's capital lost by investors when the cat bond defaults, and $\eta$ and $\kappa$ respectively reflect the representative investor's degree of risk aversion and the exposure of his own wealth to the catastrophe. Finally, $\mu$ is a loading that covers the verification costs that the investor incurs when the cat bond defaults. While the first term of equation (5) is the spread that would be required by a risk neutral investor, the second term reflects a risk premium. Finally, $D$ is a fixed underwriting cost independent of the size $K$ or probability $\pi$ of a capital loss.

Based on this model, we estimate the following regression

$$
s_{j}=\beta_{0} \pi_{j} \mathbb{E}\left(\tilde{y}_{j}\right)+\beta_{1} \pi_{j}\left[\mathbb{E}\left(\tilde{y}_{j}^{2}\right)-\pi\left(\mathbb{E} \tilde{y}_{j}\right)^{2}\right] K_{j}+\frac{\beta_{2}\left(1+\gamma_{j}^{\prime} X_{j}\right)}{K_{j}}+\varepsilon_{j},
$$

by using information from the Artemis database on cat bond transactions. ${ }^{15}$ $s_{j}$ denotes the spread over LIBOR of cat bond $j=1, \ldots, J$. If $\mathrm{m} € K_{j}$ is issued through cat bond $j$, the corresponding cost of capital incurred by the issuer is $c_{j}=s_{j} K_{j}$. The spread of cat bonds is explained by the probability of loss $\pi_{j}$, conditional expected loss per $€, \mathbb{E}\left(\tilde{y}_{j}\right)$, conditional expected loss squared, ${ }^{16}$

\footnotetext{
${ }^{14}$ In these models, either $c_{0}^{*}=c(0, K)$ is prohibitively large or $c_{\pi K}^{\prime \prime}(0, K)=+\infty$, which makes risk coverage unattractive when $\pi$ is very small.

${ }^{15}$ http://www.artemis.bm/

${ }^{16}$ We only possess information on the expected value of the variables $\tilde{y}_{j}$. We therefore
} 
capital issued $K_{j}$, and a vector of observable controls $X_{j}$, such as year of issuance and zone of peril covered that may affect the fixed underwriting cost.

The Artemis database contains more than two-hundred issues, some of which are divided into several tranches, characterized by different levels of risk, and therefore by different spreads. We restrict our analysis to 185 of the most recent tranches, spanning an interval of six years (2011-2017), for which we have complete information, including the nature of perils, types of trigger, probability of a capital loss, expected loss ${ }^{17}$ spreads, and identity of sponsors. Relevant controls also include the year of issuance, the area of the peril covered, and the type of trigger ${ }^{18}$

Table 6 gives the main OLS estimates of regression (6) 19

\begin{tabular}{cccc} 
& $\beta_{0}$ & $\beta_{1}$ & $\beta_{2}$ \\
\hline Estimates & $1.4693^{* * *}$ & $0.0027^{* *}$ & 0.5129 \\
t-stat & $(10.5472)$ & $(2.1438)$ & $(0.9366)$ \\
\hline$R^{2}$ & 0.7794 & &
\end{tabular}

All parameters are positive and consistent with theory. The first parameter $\beta_{0}$ is estimated to be 1.4693 , which indicates the presence of a loading around forty-seven percent. The second parameter $\beta_{1}$, that identifies the representative investor's risk aversion, is statistically significant at a $5 \%$ level. This second term will play an important role, due to the large values taken by $K$, the cat bond's capital. Finally, the third parameter $\beta_{2}$, that captures the cat bond's fixed cost $D$, is estimated at 0.5129 , which implies a fixed cost of $€ 512,900$. For a 100 million euros cat bond, this corresponds to a spread of $0.51 \%$ due to the fixed underwriting costs. ${ }^{20}$

Compared with alternative models, ours features three main differences that should be emphasized. First, unlike competing models, we allow for a cost of capital $c=s(\pi, K) K$ which is non-linear in $K$, giving rise to increasing marginal cost of capital. Secondly, when multiplied by $K$ the positive intercept of our regression is a fixed cost $D$ (i.e. a component of the capital

compute $\mathbb{E}\left(\tilde{y}_{j}^{2}\right)$ by making the assumption that $\tilde{y}_{j}$ is uniformly distributed over an interval $\left[a_{j}, 1\right]$. We then calibrate $a_{j}$ to match the expected value of the uniform distribution with its empirical counterpart $\mathbb{E}\left(\tilde{y}_{j}\right)$.

${ }^{17}$ The probability of a capital loss and the distribution of losses are evaluated by modeling companies independent from the sponsor and the investor.

18 Appendix 7.5 and 7.7 show that the cat bonds in our data set have characteristics similar to those used in a recent study by Braun (2015).

${ }^{19}$ The full table, along with alternative specifications is reported in Appendix 7.6

${ }^{20}$ This is probably a much more reasonable estimate than the $2.64 \%$ predicted by the standard linear model of Mahul and Lane (2000). See Appendix 7.8 
cost independent from $\pi$ and $K$ ) that can be interpreted as an underwriting cost, absent from other models. The third difference lies in that our model satisfies condition $c_{K}^{\prime} \rightarrow 0$ when $\pi \rightarrow 0$. Violation of this condition in most competing models comes from the positive intercept in the spread equation (or from a very concave relationship between the spread and the loss probability) which has no theoretical foundation ${ }^{21}$

In the model of section 2 , we have assumed $\tilde{y}=1$, which, for our cat bond, ${ }^{22}$ gives

$$
c(\pi, K)=\beta_{0} \pi K+\beta_{1} \pi(1-\pi) K^{2}+\beta_{2},
$$

and in particular

$$
c_{K \pi}^{\prime \prime}(0, K)=\beta_{0}+2 \beta_{1} K,
$$

which is an ingredient of the formula provided in Proposition 1

\section{Individual lotteries}

As in Eeckhoudt et al. (2000), we make use of the aggregate information on costs and probabilities drawn from Probabilistic Safety Assessment (PSA) studie 23 to construct individual lotteries. We consider the risk associated with one major accident on the French territory. ${ }^{24}$ The 58 French nuclear reactors are gathered into 19 power plants. Based on Eeckhoudt et al. (2000), we assume that 2 million people live around each power plant. Therefore 38 million people are located near a power plant (less than 100km) and 28 million people live further away. We index these two groups by $i=1,2$, with shares in the population $\alpha_{1}=38 / 66$ and $\alpha_{2}=28 / 66$, respectively. We let $\pi$ denote

\footnotetext{
${ }^{21}$ Appendix $\sqrt{7.8}$ shows that our model compares favorably with competing models in the literature.

${ }^{22}$ For simplicity, we have designed a simple cat bond that defaults entirely in case of a catastrophe. In addition, the cat bond we are interested in belongs, by design, to the reference group of our econometric specification, which is why the dummy controls do not appear in equation (7).

${ }^{23}$ The Probabilistic Safety Assessment (PSA) studies assess the odds and the stakes of a major accident along several dimensions: sanitary, environmental, economic, etc. They deliver probability and cost estimates for various accident scenarios, presented in Dreicer et al. (1995) and Markandya (1995). Additional studies from international agencies, such as the French Institute for Radioprotection and Nuclear Safety (IRSN, 2013) and the Nuclear Energy Agency (NEA, 2000), also develop the methodology for estimating the costs associated with the various accident scenarios predicted by PSA studies.

${ }^{24}$ The PSA studies, produced by nuclear safety agencies, develop scenarios of accident. Among these, the ST21 scenario is often used as a benchmark. We therefore use this scenario to calibrate the number of direct victims in our baseline scenario. The PSA studies referenced in the previous footnote provide the technical background on which ST21 relies.
} 
the probability that a major nuclear accident affects the territory. Most PSA studies provide very low estimates ranging from $10^{-4}$ to $10^{-9}$ per year and per reactor. We will use in our computation $\pi=58 * 10^{-5},{ }^{25}$ but since we approximate the optimal level of capital by its limit value, this calibration does not affect our results about the optimal coverage and deductible $K^{*}$, $d^{*}$, but it does affect the capital cost $c\left(\pi, K^{*}\right)$ and thus the premium $P$.

For any individual, the potential direct consequences of a nuclear accident may include financial losses, severe disease and death, ${ }^{26}$ and it is these losses that may be subject to compensation under corporate liability law. Other losses are supposed to be evenly spread over the whole population. When an accident occurs, an individual of group 1 has a probability 1/19 of living nearby the damaged power plant $(<100 \mathrm{~km}),{ }^{27}$ in which case he can die, or suffer a severe disease, or a financial loss if he is located in the plume of radioactivity. With probability 18/19, he lives away from the damaged power plant $(\geq 100 \mathrm{~km})$, similar to a person from group 2 , and can die or suffer a severe disease. The direct financial losses are incurred only by people in group 1, and may result from the impossibility to stay in a contaminated area.

We use figures similar to Eeckhoudt et al. (2000) to calibrate our baseline scenario. The number of direct victims in the baseline scenario (scenario 1) is summarized in Table 1 .

Table 1: Repartition of losses in scenario 1

\begin{tabular}{|c|c|c|c|c|}
\hline Distance & Population & Financial loss & Death & Severe disease \\
\hline$<100 \mathrm{~km}$ & 2 million & 10,000 & 500 & 1,000 \\
$\geq 100 \mathrm{~km}$ & 64 million & 0 & 3,000 & 6,000 \\
\hline
\end{tabular}

We assume that each person in the most exposed group (i.e. individuals from group 1, living within $100 \mathrm{~km}$ of a power plant) can potentially be in 6 distinct states ( 3 health states $\times 2$ financial states) $s_{1}=1, \ldots, 6$. Other individuals never incur the direct financial loss, so they can only be in three different health states $s_{2}=1, \ldots, 3$. The lotteries associated with the baseline scenario are summarized in Tables 2 and 3. The initial wealth $w$ is calibrated in euros, as the sum of the asset value currently held, plus the expected

\footnotetext{
${ }^{25}$ We neglect the possibility that accidents may occur simultaneously in several power plants.

${ }^{26}$ Severe disease and death occur due to over-exposure to radioactive material. The event of an immediate death is very unlikely and the number of deaths used in our scenarios account for the medium and long-run increase in mortality due to radiation exposure.

${ }^{27}$ For simplicity, we assume that the 19 power plants have the same number of reactors. This approximation has very little impact on our results.
} 
discounted future wealth of the average French citizen, which yields $w=$ 875,310 euros ${ }^{28}$

People from group 1 die in states $s_{1}=1$ and 2 . They also suffer a financial loss in state $s_{1}=1$ (and not in state $s_{1}=2$ ). The worst possible case is represented by the loss of a fraction $1-\omega$ of total wealth, where $\omega$ can be interpreted as a bequest parameter. We choose the parameter $\omega$ so as to match the value of a statistical life (VSL) recommended for costbenefit analysis with a HARA utility function 29 In particular, our baseline calibration with $\omega=10 \%$ implies Values of a Statistical Life between 3 and 4 million euros, consistent with the estimates provided in Viscusi and Aldi's (2003) meta-analysis and with Quinet (2013), which sets the standard for cost-benefit analysis in France 30

People in state $s_{1}=3$ do not die but they face the combined consequences of a severe disease and financial losses. In states $s_{1}=4$ and $s_{1}=5$, they suffer either the severe disease or the financial shock, respectively, while in state $s_{1}=6$ they do not incur direct losses. Table 2 presents these loss levels and the corresponding probability conditional on the occurrence of a nuclear accident 31

Concerning group 2, individuals die in state $s_{2}=1$, suffer a severe disease in state $s_{2}=2$ and face no direct loss in state $s_{2}=3$.

Table 2: Lotteries for type $i=1$

\begin{tabular}{|c|c|c|c|c|}
\hline State & Description of direct losses & Direct loss & Total loss & Probability \\
\hline$s_{1}=1$ & Death + financial loss & 787,780 & 787,780 & $7.8947 \mathrm{e}-08$ \\
$s_{1}=2$ & Death & 717,780 & 719,220 & $5.7513 \mathrm{e}-05$ \\
$s_{1}=3$ & Disease + financial loss & 330,000 & 331,440 & $1.3158 \mathrm{e}-07$ \\
$s_{1}=4$ & Disease & 260,000 & 261,440 & $1.1500 \mathrm{e}-04$ \\
$s_{1}=5$ & Financial loss & 70,000 & 71,440 & $2.6297 \mathrm{e}-04$ \\
$s_{1}=6$ & No direct loss & 0 & 1,440 & $9.996 \mathrm{e}-01$ \\
\hline
\end{tabular}

To these direct consequences, subject to compensation under corporate liability law, one must add more diffuse economic costs that are qualified as indirect costs in Schneider (1998) and subsequent studies. They are difficult to quantify and attribute to a given individual. Examples of such costs are:

\footnotetext{
${ }^{28}$ The details of this calibration are presented in Appendix 7.4 .

${ }^{29}$ In most cases, the HARA utility function does not display a divergent index of absolute risk aversion when $\omega$ goes to zero. A notable exception is the CRRA case). See equation 8 below.

${ }^{30}$ Appendix 7.9 shows the robustness of our analysis to a change in the parameter $\omega$.

${ }^{31}$ The state probabilities in Tables 2 and 3 are also conditional on belonging to group 1 and 2 , respectively.
} 
the loss of attractiveness of an impacted territory, loss in terms of image for the industrial sector, etc ${ }^{32}$ For simplicity, we assume that these costs are evenly shared by all individuals in the economy ${ }^{33}$ and we keep the total cost of the accident fixed at 100 billion euros. Individuals from group 1 in state $s_{1}=6$ and individuals from group 2 in state $s_{2}=3$ only face the indirect loss from the accident. Total losses are obtained by adding direct and indirect losses.

Alternative scenarios (scenario 2,3,4 and 5) are generated by multiplying the number of direct victims considered in Table1 by 2,3,4 and 5, respectively, while reducing the value of indirect losses so as to keep the total cost fixed at 100 billion euros. Total direct losses range from 5 billion euros in scenario 1 to approximately 25 billion euros in scenario 5 . Total indirect losses therefore vary between 75 and 95 billion euros. In tune with the more recent studies on nuclear risk (Rabl and Rabl (2013)), we consider scenario 3 as the central scenario and baseline scenario 1 as a lower bound on the consequences of a large-scale accident. Because we assume that indirect losses are mutualized, they only marginally affect the optimal coverage level. Hence, as far as corporate liability is concerned, the assumption that total cost is 100 billion euros is innocuous 34

Table 3: Lotteries for type $i=2$

\begin{tabular}{|c|c|c|c|c|}
\hline State & Description of direct losses & Direct loss & Total loss & Probability \\
\hline$s_{2}=1$ & Death & 717,780 & 719,220 & $4.6875 \mathrm{e}-05$ \\
$s_{2}=2$ & Disease & 260,000 & 261,440 & $9.3750 \mathrm{e}-05$ \\
$s_{2}=3$ & No direct loss & 0 & 1,440 & $9.999 \mathrm{e}-01$ \\
\hline
\end{tabular}

\section{Optimal coverage}

We postulate a harmonic absolute risk aversion (HARA) utility function

$$
u(x)=\frac{\gamma}{1-\gamma}\left(\eta+\frac{x}{\gamma}\right)^{1-\gamma},
$$

\footnotetext{
${ }^{32}$ Here, we do not discuss the effect of the catastrophe on growth, as the literature has not reached a consensus on the growth effect of disasters. For example, Gignoux and Menéndez (2016) find a positive effect for the case of an earthquake in India, while Strobl (2012) finds a negative effect for the case of hurricanes in the Caribbean.

${ }^{33}$ We could also treat these indirect costs as uninsurable background risks. Under the risk vulnerability assumption, these background risks would increase the degree of risk aversion to insurable risks.

${ }^{34}$ In particular, assuming a total cost of 50 or 200 billion euros would not significantly modify our results.
} 
whose domain is such that $\eta+(x / \gamma)>0$, and $u$ is increasing and concave. With affine risk tolerance $T(x)=1 / A(x)=\eta+x / \gamma$, the coefficient of relative risk aversion is

$$
R(x)=x\left(\eta+\frac{x}{\gamma}\right)^{-1} .
$$

The HARA class nests the constant relative risk aversion (CRRA) case when $\eta=0$, and the constant absolute risk aversion (CARA) case when $\gamma \rightarrow$ $+\infty$. Except for the limit case of CARA, HARA functions satisfy decreasing absolute risk aversion. In addition, when $\eta>0$, HARA functions also display increasing relative risk aversion. Studies on individual data, such as Levy (1994) and Szpiro (1986), have isolated a plausible range between 1 and 5 for the index of relative risk aversion. We therefore perform simulations over this plausible range of values.

The optimal values of the deductible and capital are deduced from Proposition 1 and Section 3 . They are reported in Table 4 for a level of relative risk aversion $\bar{R}:=R(w)=2$, which is our baseline assumption ${ }^{35}$ Since the relative risk aversion has two degrees of freedom in the HARA case, we let $\underline{R}:=R(w-L)$, where $L$ is the loss incurred in state $s_{1}=1$ by group 1 individuals, vary across columns. ${ }^{36}$ The scenario considered varies across lines.

Optimal levels of coverage (in billion euros) and their associated welfare gains are read from the top panel of Table 4. Annual premiums (in millions of euros) and deductibles (in hundreds of thousands of euros) are read from the bottom panel. The shaded cells highlights the results for a central set of assumptions with scenario $3, \underline{R}=2$ and $\bar{R}=2$ (i.e. the CRRA case), we find an optimal level of coverage $K^{*}$ equal to $€ 1.3740$ billion, an associated welfare gain of $14.72 \%$, a deductible of $€ 618,550$ per inhabitant, and an annual premium of $€ 4.6588$ million (just below 7 cents per person). This yields a spread $s=4.6588 / 1374=0.34 \% 37$ that is one order of magnitude above the spread that a risk neutral investor would require in the absence of underwriting costs. In principle, these fixed underwriting costs can be an issue for the insurability of low-probability events, but in our setting they are

\footnotetext{
${ }^{35} \mathrm{~A}$ wider set of assumptions, with an index of relative risk aversion $\bar{R}$ varying from 1 to 5 , is considered in Appendix 7.9 .

${ }^{36}$ In other words, $\bar{R}$ and $\underline{R}$ denote the index of relative risk aversion, in the no accident state and in the worst case state, respectively.

${ }^{37}$ This total spread is composed of the several components of regression (6). In particular, the spread that is due to the presence of fixed underwriting costs is equal to $\beta_{2}$ divided by the size, in hundred million euros, (13.47) of the cat-bond. This yields a spread of $0.038 \%$ due to the fixed costs. Put differently, the fixed cost component of the spread represents roughly ten percent of the total spread on a cat-bond of optimal size.
} 
Table 4: Optimal cover (in €billion), Welfare gain, Annual premium (in $€$ €millions), Deductible (in €hundreds of thousands), $\bar{R}=2$

\begin{tabular}{|c||c|c|c|c|}
\hline \multicolumn{1}{|c||}{$\underline{\mathrm{R}}$} & \multicolumn{2}{|c|}{1} & \multicolumn{2}{c|}{2} \\
\hline Scenario & Cover & Welfare & Cover & Welfare \\
\hline \hline 1 & 0.6982 & 0.0562 & 0.7636 & 0.0791 \\
\hline 2 & 0.9829 & 0.0825 & 1.1204 & 0.1213 \\
\hline 3 & 1.1693 & 0.0972 & 1.3740 & 0.1472 \\
\hline 4 & 1.3060 & 0.1056 & 1.5726 & 0.1637 \\
\hline 5 & 1.4125 & 0.1030 & 1.7360 & 0.1742 \\
\hline \hline$\underline{\mathrm{R}}$ & \multicolumn{3}{|c|}{2} \\
\hline Scenario & Premium & Deductible & Premium & Deductible \\
\hline \hline 1 & 1.8759 & 5.6588 & 2.0825 & 5.5150 \\
\hline 2 & 2.8731 & 6.1122 & 3.4459 & 5.9612 \\
\hline 3 & 3.6640 & 6.3355 & 4.6588 & 6.1855 \\
\hline 4 & 4.3138 & 6.4742 & 5.7502 & 6.3278 \\
\hline 5 & 4.8604 & 6.5708 & 6.7409 & 6.4286 \\
\hline
\end{tabular}

divided among a large number of agents and therefore have a small impact on each agent.

Table 4 highlights the dependence of the coverage and annual premium on the catastrophe scenario. When $\underline{R}=1$ and $\bar{R}=2$, multiplying the number of people in each category of loss by 5 (i.e. comparing scenario 1 and 5 ) induces an increase in cover and premium by a factor 2.02 and 2.60 , respectively. The fact that coverage increases at a slower pace than direct losses is an intuitive result that is due to the increasing marginal cost of capital.

The deductible varies between $€ 551,500$ and $€ 657,080$ in Table 4. This represents more than half of the individual's wealth, which implies that only people in the worst states $\left(s_{1}=1,2\right.$ for group 1 and $s_{2}=1$ for group 2) are indemnified. Table 4 also confirms the intuition that deductibles should decrease with risk aversion, but the effect is quantitatively limited. Finally, the deductible increases with the severity of the loss scenario, which reflects our previous remark on the effect of increasing marginal cost of capital on optimal coverage. As more capital is needed to compensate the victims with the largest losses, it is optimal to increase the deductible in order to avoid a sharp increase in premiums.

The welfare gain is computed as the reduction in the loss certainty equivalent induced by the cover in comparison with the case without any compen- 
sation 38 The welfare gain is therefore estimated at least at $14.72 \%$ under scenario 3 with $\bar{R}=2$ and $\underline{R}=2$. This means that the average monetary equivalent cost of the nuclear risk is lowered by $14.72 \%$ thanks to the indemnity schedule when $K^{*}=€ 1.3740$ billion. Of course, welfare gains for group 2 , taken separately, would be higher. Higher values for the coefficients of relative risk aversion, or a more pessimistic loss scenario would lead to much higher values of $K^{*}$ and substantially higher welfare gains.

Note finally that in scenario $3, K^{*}$ is substantially higher than the lower bound of nuclear operator's liability adopted in 2004 through the revision of the Paris convention, which is $€ 700$ million for each accident. Only scenario 1 under the assumption $\underline{R}=1$ and $\bar{R}=2$ yields an optimal liability slightly lower than $€ 700$ million, while all other cases considered here deliver higher values. The fact that several other European countries ${ }^{39}$ have set nuclear corporate liability at higher levels is coherent with such a conclusion.

\section{Conclusion}

The purpose of this paper was to characterize the socially optimal insurance scheme against nuclear disasters. We have shown that, in the case of a large-scale low-probability industrial catastrophe, the asymptotic indemnity schedule is characterized by a straight deductible, common to all individuals.

Based on this result, we have analyzed the features of an optimal insurance scheme that covers the nuclear corporate liability, in which the risk is transferred to financial markets through cat bonds. Using recent cat bond data and safety studies on nuclear reactors allows us to compute the optimal level of coverage. Our results, calibrated with French data, suggest that the nuclear liability law should be more ambitious than it currently is, unlike in other countries, such as Germany, where this liability has been extended far

\footnotetext{
${ }^{38}$ Since group 1 and group 2 do not face the same risk exposure, this reduction differs from one group to the other. The figure presented in Table 4 is an average of these two gains weighted by group size.

${ }^{39}$ Countries have their own legislation, in line with international conventions. For instance, in Germany, the nuclear corporate liability is set at $€ 2.5$ billion for each accident. This could be rationalized in our model with scenarios more severe than our scenario 5, or with higher levels of risk aversion, such as the ones considered in Appendix 7.9. Note that the Paris convention also specifies tranches of liability born by governments, so that total liability toward the victims are at least $€ 1.5$ billion. These additional coverage tranches however, are also intended to indemnify victims across the borders of the state where the accident occurred. The Paris and Brussels conventions indeed provide that the state where the accident took place is liable toward foreign victims. We therefore consider in this paper that only the tranche supported by the operators and secured by a proper insurance scheme represent a coverage available to the citizens of a country.
} 
beyond the requirements of international conventions. In France, the ratification of the 2004 Protocol was made difficult by the large induced capital costs, but also by the insurers' reluctance to extend the validity of healthrelated claims to thirty years and by the conservative position of the nuclear industry.

Our analysis presents a certain number of limits that we shall now discuss. First, we have implicitly assumed that market insurance is the only tool available to deal with catastrophic risk. In practice, individuals and societies have other means at their disposal. The effect of self-insurance -a reduction in the size of the loss- and self-protection -a reduction in the loss probabilitywere studied in a seminal paper by Ehrlich and Becker (1972). Because market insurance and self-insurance are perfect complements, our theoretical results could be readily adapted to self-insurance. On the other hand, Ehrlich and Becker have shown that self-protection and market insurance, can be complements. The complex analysis of the interaction between self-insurance, self-protection and market insurance for catastrophic risk is not addressed in our model and is left for further research.

Our conclusions should also be put in the broader context of how law be it in the common law or civil law traditions - defines corporate liability, and how the liability regime affects the role of insurance. ${ }^{40}$ Based on the international conventions on nuclear tort law, we have assumed that liability is strict. As opposed to a negligence rule, strict liability dictates that a nuclear operator must indemnify victims in case of accident, whether or not he was negligent. This strict liability avoids time-consuming litigation about who the liable entity is, hence facilitating a prompt indemnification of victims. Another approach would consist in adopting the negligence rule, according to which the operator of the nuclear installation is held liable for accident losses only if it exercised a level of care lower than a level specified by courts, hence without liability cost for a firm that complied with safety regulation. The main drawbacks of the negligence rule when applied to corporate nuclear liability are related to the difficulties for courts to establish that the nuclear operator did not exercise due care levels. This weakens the incentives for risk prevention and, furthermore, it opens the door to legal actions that create obstacles to the rapid compensation of victims. If, after an accident, the court considers that the operator has not been negligent and should be exonerated from liability, then the negligence rule shifts the compensation of victims from corporate liability insurance onto the government's budget. The cost of public fund would then be a key ingredient of the optimal liability

\footnotetext{
${ }^{40}$ For more on the impact of tort law on incentives, see Shavell (1987) and Cooter and Ulen (2004).
} 
level.

In a dynamic model with uninsurable risk, prudent agents save to constitute a buffer stock, used in case of loss. If market insurance is sold at actuarially fair prices, expected utility maximizing agents should purchase full insurance and make no precautionary savings. However, positive insurance loadings may lower the demand for market insurance, substituted with precautionary savings. Gollier (2003) showed, with a calibrated example, that the demand for market insurance may become quite low whenever assets enable agents to transfer wealth across periods. However, his example only discusses the case of small losses. The strategy of substituting market insurance with precautionary savings would not be feasible at the level of individual agents who risk up to their lives. It could more realistically be set up at the level of a state who would face a choice between a funded and a pay-as-you-go system, in which it simply borrows when a catastrophe occurs. Both strategies would entail benefits comparable to the insurance scheme proposed in our paper but would involve a cost of public fund. In this regard, Borensztein et al. (2017) show that cat bonds may yield substantial gains to governments, for they lower their risk of default in case of catastrophe. This suggests that funding the coverage of catastrophic risks through cat bonds, and transferring losses to future periods through credit markets should not be seen as substitutes: they are complements. 


\section{Appendix}

\subsection{Complement to section 2.1}

Let us assume that the government can redistribute wealth between groups through ex ante lump sum transfers. We denote $t_{i}$ the net transfer paid to each individual of group $i$, the government budget constraint being written as

$$
\sum_{i=1}^{n} \alpha_{i} t_{i}=0
$$

Now we have

$$
\begin{aligned}
w_{1} & =w-P+t_{i}, \\
w_{2 i}\left(x_{i}\right) & =w-P-x_{i}+I_{i}\left(x_{i}\right)+t_{i} .
\end{aligned}
$$

and the certainty equivalent loss incurred by type $i$ individuals is still denoted by $C_{i}$, with

$$
\begin{aligned}
u\left(w-C_{i}+t_{i}\right)= & \left(1-\pi q_{i}\right) u\left(w_{1}+t_{i}\right) \\
& +\pi q_{i} \int_{0}^{\bar{x}_{i}} u\left(w_{2 i}\left(x_{i}\right)+t_{i}\right) f\left(x_{i}\right) d x_{i} .
\end{aligned}
$$

An allocation is written as $\mathcal{A}=\left\{w_{1}, w_{21}\left(x_{1}\right), \ldots, w_{2 n}\left(x_{n}\right), C_{1}, \ldots, C_{n}, t_{1}, \ldots, t_{n}, K\right\}$, and $\mathcal{A}$ is feasible if (2), (3), (4) and (9) are satisfied.

Definition $1 \mathcal{A}$ is Pareto-optimal if it is feasible and if there does not exist another feasible allocation $\widehat{\mathcal{A}}=\left\{\widehat{w}_{1}, \widehat{w}_{21}\left(x_{1}\right), \ldots, \widehat{w}_{2 n}\left(x_{n}\right), \widehat{C}_{1}, \ldots, \widehat{C}_{n}, \widehat{t}_{1}, \ldots, \widehat{t}_{n}, \widehat{K}\right\}$ such that $\widehat{C}_{i}-\widehat{t}_{i} \leq C_{i}-t_{i}$ for all $i=1, \ldots, n$, with $\widehat{C}_{i_{0}}-\widehat{t}_{i_{0}}<C_{i_{0}}-t_{i_{0}}$ for at least one group $i_{0}$.

Proposition $2 \mathcal{A}=\left\{w_{1}, w_{21}\left(x_{1}\right), \ldots, w_{2 n}\left(x_{n}\right), C_{1}, \ldots, C_{n}, t_{1}, \ldots, t_{n}, K\right\}$ is a Paretooptimal allocation if and only if it minimizes $\sum_{i=1}^{n} \alpha_{i} C_{i}$ in the set of feasible allocations.

\subsection{A cat bond pricing model}

This section presents the cat bond pricing model. The cat bond is issued at $t=0$. Part of its capital is used at time $t=0$ to pay the underwriting costs and the remainder constitutes the principal. At time $t=1$ the principal $K$ is returned to the investor if the accident did not occur. In the opposite case, the cat bond defaults and the sponsor uses a fraction $\tilde{y}$ of the capital to indemnify the victims. The remaining portion of capital is returned to 
the investors. From the standpoint of the investor, the cat bond 's payoff is therefore

$$
\tilde{q}=\left\{\begin{array}{clc}
(1+R) K-(1+\mu) \tilde{y} K & \text { with probability } & \pi, \\
(1+R) K & \text { with probability } & 1-\pi .
\end{array}\right.
$$

In compensation for the option to default on the principal, the investors require a coupon of rate $R=r+s$, where $r$ denotes the risk free rate and $s$ denotes the spread. We let $D /(1+r)$ be the value of the underwriting costs (i.e. $D$ is the corresponding value at time $t=1$ ), and $\mu$ is a loading that covers the verification costs.

Let $C E$ be the certainty equivalent of the cat bond payoff $\tilde{q}$ to investors at time $t=1$. Following the Consumption Capital Asset Pricing Model, we write

$$
C E=\mathbb{E} \tilde{q}-\eta \operatorname{cov}(\tilde{z}, \tilde{q}),
$$

where $\tilde{z}$ denotes the wealth of the representative investor at $t=1$, and $\eta$ reflects his risk aversion. There are two states: with probability $\pi$, the accident occurs, the cat bond defaults and investors suffer a loss $(1+\mu) \tilde{y} K$; with probability $1-\pi$, the accident does not occur and the principal is returned to the investor. In both cases, the coupon $R K$ is paid to the investor ${ }^{41} \mathrm{We}$ assume that the representative investor bears a fraction $\kappa$ of the underlying loss 42 We therefore write

$$
\tilde{z}=\left\{\begin{array}{clc}
w-\kappa K \tilde{y} & \text { with probability } & \pi \\
w & \text { with probability } & 1-\pi .
\end{array}\right.
$$

Thus

$$
\begin{aligned}
\mathbb{E} \widetilde{q} & =[R+1-\pi(1+\mu) \mathbb{E}(\tilde{y})] K, \\
\operatorname{cov}(\widetilde{z}, \widetilde{q}) & =(1+\mu) \kappa \pi\left[\mathbb{E}\left(\tilde{y}^{2}\right)-\pi(\mathbb{E} \tilde{y})^{2}\right] K^{2} .
\end{aligned}
$$

and

$$
C E=[R+1-\pi(1+\mu) \mathbb{E}(\tilde{y})] K-\eta(1+\mu) \kappa \pi\left[\mathbb{E}\left(\tilde{y}^{2}\right)-\pi(\mathbb{E} \tilde{y})^{2}\right] K^{2} .
$$

\footnotetext{
${ }^{41}$ Hence we assume that default affects the repayment of the capital to the investor first. The coupon payment is affected only when the loss $\tilde{y}$ is very large and $1-(1+\mu) \tilde{y}$ becomes negative. This assumption is made for simplicity, but of course other definitions of cat bonds are possible.

${ }^{42}$ We do not restrict $\kappa$ and will estimate it from the data. From a theoretical perspective, the precise value of $\kappa$ depends on the identity of the representative investor. If the representative investor is not exposed to the underlying risk transferred by the cat bond, we should have $\kappa \equiv 0$.
} 
Purchasing the cat bond is analogous to making an investment $K$ with additional cost $D /(1+r)$ at $t=0$ and random payoff $\widetilde{q}$, with certainty equivalent $C E$, at $t=1$. Thus, in the absence of arbitrage, we have

$$
K+\frac{D}{1+r}=\frac{C E}{1+r}
$$

which may be rewritten as

$K(1+r)=[R+1-\pi(1+\mu) \mathbb{E}(\tilde{y})] K-\eta(1+\mu) \kappa \pi\left[\mathbb{E}\left(\tilde{y}^{2}\right)-\pi(\mathbb{E} \tilde{y})^{2}\right] K^{2}-D$.

Let $s=R-r$ be the spread over the risk-free rate. We obtain

$$
s=\pi(1+\mu) \mathbb{E}(\tilde{y})+\eta \kappa(1+\mu) \pi\left[\mathbb{E}\left(\tilde{y}^{2}\right)-\pi(\mathbb{E} \tilde{y})^{2}\right] K+\frac{D}{K} .
$$

In order to estimate this equation on our data set, we assume each $\tilde{y}_{j}$ is uniformly distributed in an interval $\left[a_{j}, 1\right]$. This enables us to find $\mathbb{E}\left(\tilde{y}_{j}{ }^{2}\right)$ which, in turn, leads to the regression performed in section $3{ }^{43}$ We only have one loss scenario in our numerical analysis. Hence, the cat bond must completely default in case of accident, which implies that $\mathbb{E}(\tilde{y})=1$ for our cat bond. The cost of capital $c(\pi, K) \equiv s(\pi, K) K$ is therefore

$$
c(\pi, K)=\pi(1+\mu) K+\eta \kappa(1+\mu) \pi(1-\pi) K^{2}+D,
$$

which is coherent with the assumptions used to derive Proposition 1.

\subsection{Proofs}

\section{Proof of Proposition 1}

The planner's program is to minimize $\sum_{i} \alpha_{i} C_{i}$ under constraints (1), (2), (3) and (4). The Kuhn-Tucker multipliers associated with each set of constraints are respectively $\gamma_{i}, \phi_{i}\left(x_{i}\right), \eta$ and $\rho$. The optimality conditions are

$$
\begin{gathered}
\alpha_{i}-\gamma_{i} u^{\prime}\left(w-C_{i}\right)=0 \\
\gamma_{i} \pi q_{i} u^{\prime}\left(w_{2 i}\left(x_{i}\right)\right) f_{i}\left(x_{i}\right)-\eta(1+\lambda) \alpha_{i} q_{i} f_{i}\left(x_{i}\right)+\phi_{i}\left(x_{i}\right)=0, \\
u^{\prime}\left(w_{1}\right) \sum_{i=1}^{n}\left(1-\pi q_{i}\right) \gamma_{i}-\sum_{i=1}^{n} \int_{0}^{\bar{x}_{i}} \phi_{i}\left(x_{i}\right) d x_{i}-\rho+\eta(1+\lambda) \sum_{i=1}^{n} \alpha_{i} q_{i}=0, \\
-\eta+\rho c_{K}^{\prime}(\pi, K)=0, \\
\phi_{i}\left(x_{i}\right) \geq 0 \quad \text { and } \quad \phi_{i}\left(x_{i}\right)=0 \quad \text { if } \quad w_{2 i}\left(x_{i}\right)-w_{1}+x_{i}>0 \quad \forall i .
\end{gathered}
$$

\footnotetext{
${ }^{43}$ The Artemis data base provides $\pi_{j}$ and $\mathbb{E} \tilde{y}_{j}$ for each cat bond $j$ in the sample. We deduce $\mathbb{E}\left(\tilde{y}_{j}\right)^{2}$.
} 
Let $x_{i}$ be such that $w_{2 i}\left(x_{i}\right)-w_{1}+x_{i}>0$. Thus, we have $\phi_{i}\left(x_{i}\right)=0$ from (15), and (12) gives

$$
\pi \gamma_{i} u^{\prime}\left(w_{2 i}\left(x_{i}\right)\right)=\eta(1+\lambda) \alpha_{i}
$$

(11) and (16) yield

$$
u^{\prime}\left(w_{2 i}\left(x_{i}\right)\right)=\frac{\eta}{\pi}(1+\lambda) u^{\prime}\left(w-C_{i}\right) .
$$

Hence, if there exist $x_{i}^{0}, x_{i}^{1} \in\left[0, \bar{x}_{i}\right]$ such that $w_{2 i}\left(x_{i}^{0}\right)-w_{1}+x_{i}^{0}>0$ and $w_{2 i}\left(x_{i}^{1}\right)-w_{1}+x_{i}^{1}>0$, then we must have

$$
u^{\prime}\left(w_{2 i}\left(x_{i}^{0}\right)\right)=u^{\prime}\left(w_{2 i}\left(x_{i}^{1}\right)\right)
$$

which implies

$$
w_{2 i}\left(x_{i}^{0}\right)=w_{2 i}\left(x_{i}^{1}\right) .
$$

Consequently, $w_{2 i}\left(x_{i}\right)$ is constant over the set of $x_{i}$ for which $w_{2 i}\left(x_{i}\right)-w_{1}+$ $x_{i}>0$, and we can write

$$
w_{2 i}\left(x_{i}\right)=w_{1}-d_{i},
$$

with $d_{i}<x_{i}$ for all $x_{i}$ in this set, and from 17 we have

$$
u^{\prime}\left(w_{1}-d_{i}\right)=\frac{\eta}{\pi}(1+\lambda) u^{\prime}\left(w-C_{i}\right) .
$$

Now let $x_{i}$ be such that $w_{2 i}\left(x_{i}\right)-w_{1}+x_{i}=0$. Using (11), (12) and (15) allows us to write

$$
u^{\prime}\left(w_{2 i}\left(x_{i}\right)\right)=u^{\prime}\left(w_{1}-x_{i}\right) \leq \frac{\eta}{\pi}(1+\lambda) u^{\prime}\left(w-C_{i}\right) .
$$

Using (17), and $u^{\prime \prime}<0$ we deduce $x_{i} \leq d_{i}$. Thus, we have established that there exists $d_{i}$ such that

$$
\begin{array}{lll}
w_{2 i}\left(x_{i}\right)=w_{1}-d_{i} & \text { if } & x_{i}>d_{i} \\
w_{2 i}\left(x_{i}\right)=w_{1}-x_{i} & \text { if } & x_{i} \leq d_{i} .
\end{array}
$$

Let $K \rightarrow K^{*}$ when $\pi \rightarrow 0$ and $c_{0}^{*} \equiv \lim _{\pi \rightarrow 0} c\left(\pi, K^{*}\right)$. When $\pi \rightarrow 0$, we have $w_{1} \longrightarrow w-c_{0}^{*}$ and $C_{i} \longrightarrow c_{0}^{*}$ from (4) and (1) respectively. (18) then gives $d_{i} \longrightarrow d^{*} \quad \forall i$ with

$$
u^{\prime}\left(w-d^{*}\right)=(1+\lambda) u^{\prime}\left(w-c_{0}^{*}\right) \lim _{\pi \rightarrow 0} \frac{\eta}{\pi} .
$$


Using (11), (13), 114) and $\sum_{i=1}^{n} \alpha_{i}=1$ imply

$$
\lim _{\pi \rightarrow 0}\left[1-\frac{\eta}{c_{K}^{\prime}\left(\pi, K^{*}\right)}+\eta(1+\lambda) \sum_{i=1}^{n} \alpha_{i} q_{i}-\sum_{i=1}^{n} \int_{0}^{\overline{x_{i}}} \phi_{i}\left(x_{i}\right) d x_{i}\right]=0 .
$$

Suppose that $\eta$ does not go to zero when $\pi$ does. In such a case, we would have $\eta / c_{K}^{\prime}\left(\pi, K^{*}\right) \longrightarrow+\infty$ when $\pi \longrightarrow 0$ since $c_{K}^{\prime}\left(\pi, K^{*}\right) \longrightarrow 0$, and thus

$$
\lim _{\pi \rightarrow 0}\left[\eta\left[\frac{1}{c_{K}^{\prime}\left(\pi, K^{*}\right)}-(1+\lambda) \sum_{i=1}^{n} \alpha_{i} q_{i}\right]\right]=+\infty .
$$

Since $\phi_{i}\left(x_{i}\right) \geq 0 \quad \forall i$, this is in contradiction with $(22)$. Thus, we have

$$
\lim _{\pi \longrightarrow 0}\left[1-\frac{\eta}{c_{K}^{\prime}\left(\pi, K^{*}\right)}-\sum_{i=1}^{n} \int_{0}^{\overline{x_{i}}} \phi_{i}\left(x_{i}\right) d x_{i}\right]=0 .
$$

If $d_{i} \leq 0$, we have $w_{2 i}\left(x_{i}\right)-w_{1}+x_{i}>0$ and $\phi_{i}\left(x_{i}\right)=0 \quad \forall x_{i}>0$. Hence

$$
\int_{0}^{\overline{x_{i}}} \phi_{i}\left(x_{i}\right)=0 \text {. }
$$

If $d_{i}>0$, we have $\phi_{i}\left(x_{i}\right)=0$ for $x_{i}>d_{i}$, and thus (11), (12) and (20) give

$$
\begin{aligned}
\int_{0}^{\overline{x_{i}}} \phi_{i}\left(x_{i}\right) d x_{i} & =\int_{0}^{d_{i}} \phi_{i}\left(x_{i}\right) d x_{i} \\
& =-\pi \alpha_{i} q_{i} \int_{0}^{d_{i}}\left[\frac{u^{\prime}\left(w-x_{i}\right)}{u^{\prime}\left(w-C_{i}\right)}-\frac{\eta}{\pi}(1+\lambda)\right] f_{i}\left(x_{i}\right) d x_{i} .
\end{aligned}
$$

Using the fact that $\eta \longrightarrow 0$ when $\pi \longrightarrow 0$ gives

$$
\lim _{\pi \rightarrow 0} \int_{0}^{\overline{x_{i}}} \phi_{i}\left(x_{i}\right) d x_{i}=0
$$

and from 23 we derive

$$
\lim _{\pi \rightarrow 0} \frac{\eta}{c_{K}^{\prime}\left(\pi, K^{*}\right)}=1 .
$$

Using (21) together with L'hôpital's rule, we finally deduce

$$
\begin{aligned}
u^{\prime}\left(w-d^{*}\right) & =(1+\lambda) u^{\prime}\left(w-c_{0}^{*}\right) c_{\pi K}^{\prime \prime}\left(0, K^{*}\right) \\
& >u^{\prime}(w),
\end{aligned}
$$

where the last inequality derives from $\lambda>0$ and $c_{\pi K}^{\prime \prime}\left(0, K^{*}\right) \geq 1$. Using $u^{\prime \prime}<0$ gives $d^{*}>0$. Since $I_{i}\left(x_{i}\right)=w_{2 i}\left(x_{i}\right)+x_{i}-w_{1}$, we deduce that $I_{i}\left(x_{i}\right) \longrightarrow I^{*}\left(x_{i}\right)=\max \left(x_{i}-d^{*}, 0\right)$ when $\pi \longrightarrow 0$. 


\section{Proof of Proposition 2}

Assume that $\mathcal{A}$ minimizes $\sum_{i=1}^{n} \alpha_{i} C_{i}$ in the set of feasible allocations, and suppose that it is not Pareto-optimal, then there exists a feasible allocation $\widehat{\mathcal{A}}$ and a group $i_{0}$ such that $\widehat{C}_{i}-\widehat{t}_{i} \leq C_{i}-t_{i}$ for all $i$ and $\widehat{C}_{i_{0}}-\widehat{t}_{i_{0}}<C_{i_{0}}-t_{i_{0}}$. Consequently,

$$
\sum_{i=1}^{n} \alpha_{i}\left(\widehat{C}_{i}-\widehat{t}_{i}\right)<\sum_{i=1}^{n} \alpha_{i}\left(C_{i}-t_{i}\right)
$$

Since $\mathcal{A}$ and $\widehat{\mathcal{A}}$ are feasible, we have

$$
\sum_{i=1}^{n} \alpha_{i} t_{i}=\sum_{i=1}^{n} \alpha_{i} \widehat{t}_{i}=0
$$

and thus 26 and 27 give

$$
\sum_{i=1}^{n} \alpha_{i} \widehat{C}_{i}<\sum_{i=1}^{n} \alpha_{i} C_{i}
$$

which contradicts the fact that $\mathcal{A}$ minimizes $\sum_{i=1}^{n} \alpha_{i} C_{i}$ in the set of feasible allocations.

Conversely, assume that $\mathcal{A}$ is a Pareto-optimal allocation, and suppose that it does not minimize $\sum_{i=1}^{n} \alpha_{i} C_{i}$ in the set of feasible allocations. Thus there exists a feasible allocation $\widehat{\mathcal{A}}$ such that $\sum_{i=1}^{n} \alpha_{i} \widehat{C}_{i}<\sum_{i=1}^{n} \alpha_{i} C_{i}$, and thus

$$
\sum_{i=1}^{n} \alpha_{i}\left(\widehat{C}_{i}-\widehat{t}_{i}\right)<\sum_{i=1}^{n} \alpha_{i}\left(C_{i}-t_{i}\right) .
$$

Let us choose $\widehat{t}_{i}$ such that

$$
\widehat{t}_{i}=\widehat{C}_{i}+t_{i}-C_{i}
$$

for all $i \neq i_{i_{0}}$, which does not contradict the feasibility of $\widehat{\mathcal{A}}$ if we choose

$$
\widehat{t}_{i_{0}}=-\sum_{i \neq i_{0}} \widehat{t}_{i}
$$

We have

$$
\widehat{C}_{i}-\widehat{t}_{i}=C_{i}-t_{i} \text { for all } i \neq i_{0} .
$$

Furthermore, (28), 29) and 30 give

$$
\widehat{C}_{i_{0}}-\widehat{t}_{i_{0}}<C_{i_{0}}-t_{i_{0}} .
$$

(30) and (31) contradict the fact that $\mathcal{A}$ is Pareto-optimal. 


\subsection{Calibration of initial wealth and losses}

INSEE, the French national statistical agency, provides an average estimated Gross National Product per capita of 32,227 euro ${ }^{44}$ and an average age of 39.2 year old ${ }^{45}$. The French National Institute on Demographics (INED) provides an estimated life expectancy of 73.2 for the average $39.2^{46}$ years old citizen. Lifetime wealth is obtained as the annual GDP per capita discounted at a $2 \%$ rate on a 34 year horizon. This yields an expected discounted future wealth of 805,310 euros. INSEE also provides an estimated average of 70,000 euros of current assets, which will be the financial loss that victims may incur. We therefore consider that initial wealth is 875,310 euros.

\subsubsection{Group 1}

The worst case scenario is a fatal outcome that occurs in states $s_{1}=1$ and 2. As in Eeckhoudt et al. (2000) we assume that when this worst state materializes, the individual (in practice, her heir) is only able to retain a fraction, equal to $\omega=10 \%$ of her initial wealth, that can be interpreted as a bequest parameter. In state $s_{1}=2$, the agent dies but does not suffer the financial loss. Direct losses in these catastrophic states are therefore equal to $875,310(1-\omega)=787,780$ in state $s_{1}=1$ and $875,310(1-\omega)-70,000=$ 717,780 in state $s_{1}=2$. In state $s_{1}=3$, the agent suffers a severe health loss due to exposure to radioactivity, as well as a direct financial loss of all her financial assets. The cost of health treatment and the health induced reduction in future income is estimated in Eeckhoudt et al.(2000) at 260,000 euros. The direct loss in this state is therefore equal to 330,000 euros. In state $s_{1}=4$, the agent faces the 260,000 euros health loss and in state $s_{1}=5$, he faces the 70,000 euros financial loss.

Total losses are obtained by adding to the direct losses the indirect cost of the accident, assumed to be mutualized between all the agents who did not die. In the baseline scenario, the indirect loss is 1,440 euros per inhabitant.

\subsubsection{Group 2}

Agents in group 2 die in state $s_{2}=1$, face a severe disease in state $s_{2}=2$ and a financial loss in state $s_{2}=3$. Their direct losses are therefore calibrated at 717,780 and 260,000 euros.

\footnotetext{
${ }^{44} \mathrm{http}: / /$ www.bdm.insee.fr

${ }^{45}$ http://www.insee.fr/

${ }^{46}$ http://www.ined.fr/
} 
Table 5: Descriptive statistics for the 185 cat bonds

\begin{tabular}{|lccccc|}
\hline Variable & Mean & Median & S.D. & Max & Min \\
\hline Spread & 0.0638 & 0.0525 & 0.0392 & 0.2000 & 0.0175 \\
Expected loss & 0.0235 & 0.0160 & 0.0232 & 0.1306 & 0.0001 \\
Size (€million) & 134.86 & 108.8984 & 113.6927 & 1128.8 & 17.9453 \\
\hline
\end{tabular}

\subsection{Descriptive statistics}

Table 5 provides the summary statistics for the main variables. At 6.38\%, the average spread is lower than in Braun (2015) who finds an average of $8.18 \%$ for the period 1997-2012. Average expected loss is very close to Braun (2015) (2.35\% versus $2.08 \%$ ) and the average value of capital issued (size) is higher in our data set (134.86 €million versus 97.34 €million), perhaps due to our inability to observe small private transactions.

\subsection{OLS Estimates}

Table 6 provides the estimates of regression (6) for our fully specified model, by excluding the fixed cost and/or the risk premium among the explanatory variables. Our preferred specification, used to compute the cost of capital in the main text, is given in the three first columns. Expected loss, Risk premium and Size, respectively represent the terms $\pi_{j} \mathbb{E}\left(\tilde{y}_{j}\right), \pi_{j}\left[\mathbb{E}\left(\tilde{y}_{j}^{2}\right)-\right.$ $\left.\pi_{j}\left(\mathbb{E} \tilde{y}_{j}\right)^{2}\right] K_{j}$, and $K_{j}^{-1} .2017$, Europe and Indemnity are the reference groups for the times dummies, the geographical area covered, and the trigger types, respectively. The coefficient estimates of Expected loss and Risk premium are positive and significant across the four specifications. Concerning the control variables, 2012 was a period of high prices, followed by a decline from 2013 to 2016. The geographical dummies point at the fact that cat bonds covering perils in the US are more expensive than in other countries. This is in accordance with Braun (2015). Table 6 also shows that parametric triggers have a lower spread than indemnity triggers, which may be explained by the lower moral hazard entailed by parametric triggers. Finally, the variables $R M S$, EQECAT and MILL (Milliman) represent three of the four risk modelers that were in charge of the deal. The reference group was taken to be the risk modeler AIR.

The four regressions highlight the important role played by the risk premium term. We report, in the penultimate line of each table, the optimal level of coverage under scenario 3 and assumption $\underline{R}=\bar{R}=2$. Without the risk premium term, the marginal cost of capital would be constant, hence the higher levels of coverage reporter at the bottom of columns 8 and 11 . On 
the other hand, the fixed cost term does not play a quantitatively important role. It is indeed divided among a large number of people, and therefore represents only a few cents per person. The last lines of each table report the premium paid under the same set of assumptions. 


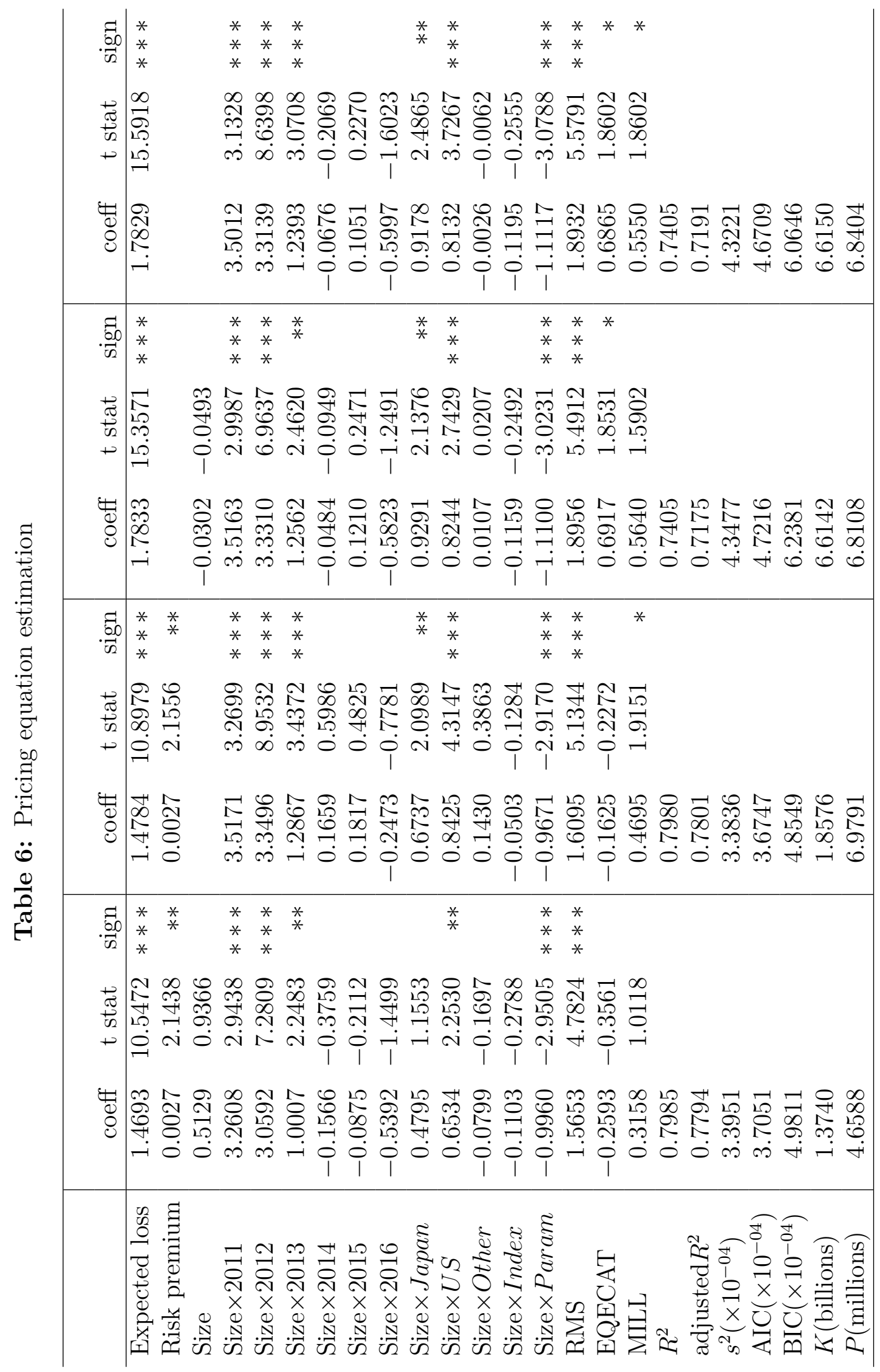




\subsection{Comparison with alternative data set}

This section compares our data set with Braun (2015)'s. In order to do so, we compare the four cat bond pricing models estimated in Braun (2015), on a sample of 466 cat bond tranches covering a period from 1997 to 2012 (Table 7), with the same models estimated on our data set (Table 8). The first model specifies spreads as a linear function of expected loss

$$
s_{j}=\hat{\alpha}+\hat{\beta} \pi_{j} \mathbb{E}\left(\tilde{y}_{j}\right) .
$$

The second model has spread as a polynomial of the natural logarithm of the expected loss

$$
s_{j}=\hat{\alpha}+\hat{\beta} \ln \pi_{j} \mathbb{E}\left(\tilde{y}_{j}\right)+\hat{\gamma}\left[\ln \pi_{j} \mathbb{E}\left(\tilde{y}_{j}\right)\right]^{2} .
$$

The third model is from Lane (2000) and specifies

$$
s_{j}=\pi_{j} \mathbb{E}\left(\tilde{y}_{j}\right)+\hat{\alpha} \pi_{j}^{\hat{\beta}} \mathbb{E}\left(\tilde{y}_{j}\right)^{\hat{\gamma}} .
$$

Finally, Major and Kreps' (2002) model posits

$$
s_{j}=\hat{\alpha}\left(\pi_{j} \mathbb{E}\left(\tilde{y}_{j}\right)\right)^{\hat{\beta}} .
$$

For comparison purposes, spreads are converted into basis points and expected losses are expressed in percentage points. Tables 7 and 8 display very similar estimates. All variables are significant, except $\hat{\gamma}$ estimated in Lane's (2000) model, both with our own and Braun's (2015) data sets.

\subsection{Comparison with alternative models}

This section compares our model to alternative models reviewed in Braun (2015). These models mostly aim at reflecting the practice of commercial reinsurers concerned by the comparative costs of various risk transfer instruments. In particular, Major and Kreps (2002) consider simultaneously the pricing of reinsurance and cat bond tranches. Models (32), (33), (34) and (35) are estimated on our data base (Table 10) and compared to our preferred specification (Table 6). To allow for a fair comparison, we augment models (32), (33), 34) and (35) with the same controls as in our preferred specification.

Table 9 summarizes our preferred specification to the alternative models in terms of adjusted $R^{2}$, sum of the squared residuals $\left(s^{2}\right)$, Akaike Information Criterion (AIC) and Bayesian Information Criterion (BIC). The four measures yield the same ordering. Our preferred specification performs slightly below models (32), 33) but significantly higher than models (34) and (35). 

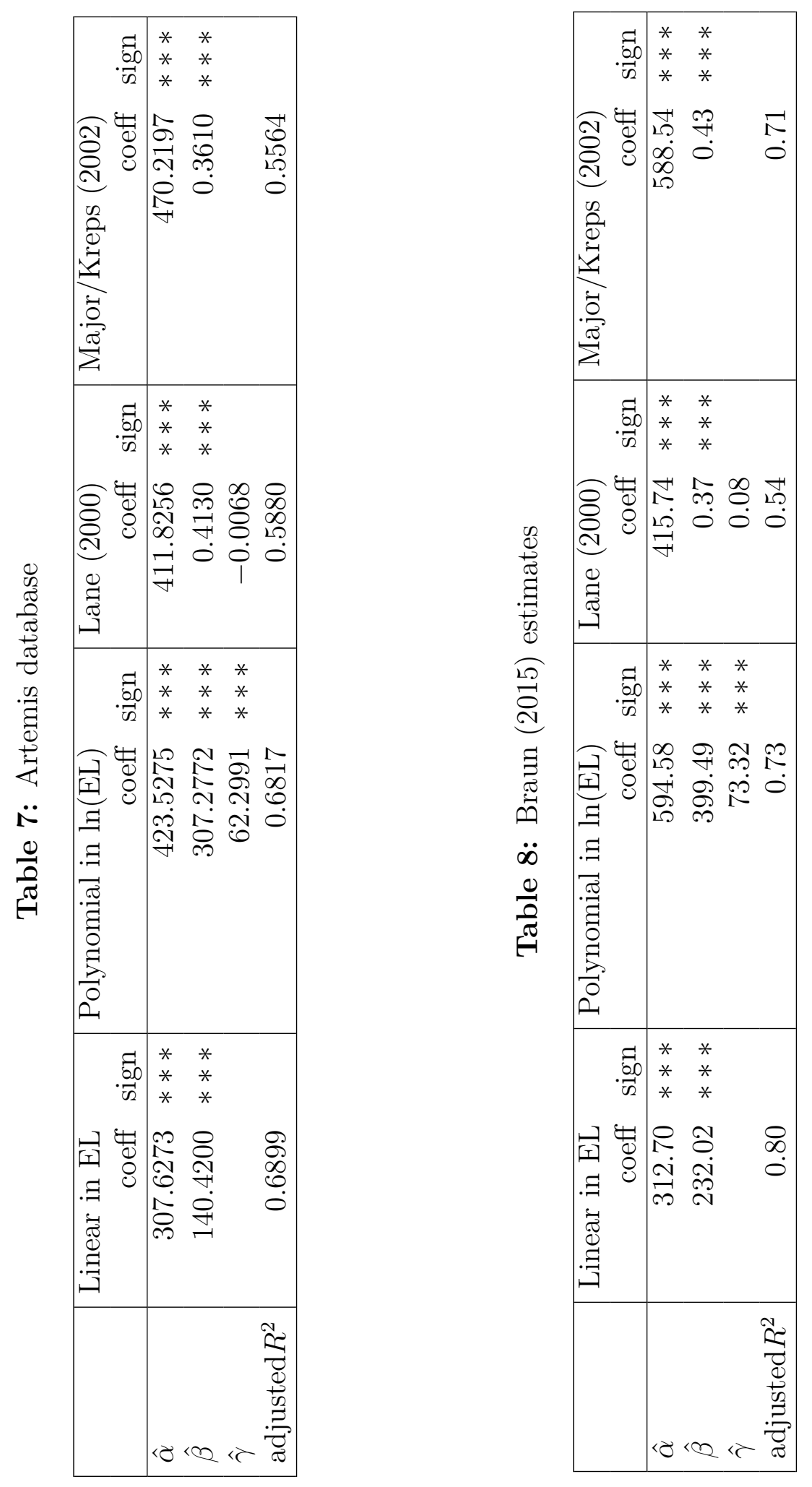
Table 9: Model comparisons

\begin{tabular}{|lccccc|}
\hline Model & $(6)$ & $(32)$ & $(33)$ & $(34)$ & $(35)$ \\
\hline Adjusted $R^{2}$ & 0.7794 & $0 . \overline{8391}$ & $0 . \overline{8146}$ & $0 . \overline{5613}$ & $0 . \overline{7244}$ \\
$s^{2}\left(\times 10^{-04}\right)$ & 3.3951 & 2.4764 & 2.8531 & 1188 & 927 \\
$\mathrm{AIC}\left(\times 10^{-04}\right)$ & 3.7051 & 2.6894 & 3.1137 & 1296 & 1007 \\
$\mathrm{BIC}\left(\times 10^{-04}\right)$ & 4.9811 & 3.5532 & 4.1860 & 1743 & 1330 \\
\hline
\end{tabular}

\subsection{Robustness analysis}

Finally, Tables 11 to 20 summarize the robustness of our numerical results of section 3 . Each table presents either optimal coverage or welfare gain for a given set of hypotheses. The cost of handling claims is set to $\lambda=0.3$, which is viewed as a reasonable estimate in the literature. However, changes in this parameter have a very limited impact on the simulation results. The scenarios that are considered vary across lines. All results are expressed in euros. Within each table, we fix $\bar{R}$ and let $\underline{R}$ vary through the columns. From left to right, we therefore increase the agent's risk aversion. For each level of $\bar{R}$ we provide two tables. The first delivers our estimates for the optimal level of coverage and the second computes the welfare gain relative to the no-coverage situation.

The most sensitive parameter is usually the subsistence level $\omega$. Our results indicate that, while the optimal coverage is robust to changes in $\omega$, the estimated welfare gains are quite sensitive. As expected, optimal coverage increases with the severity of the scenario under consideration and with the degree of risk aversion. 
7.9.1 Optimal coverage and welfare gains with $\omega=0.90$

Table 11: Coverage, $\bar{R}=1$

\begin{tabular}{|c||c|c|}
\hline \multicolumn{1}{|c||}{$\underline{\mathrm{R}}$} & \multicolumn{2}{|c|}{1} \\
\hline Scenario & Cover & Welfare \\
\hline \hline 1 & 0.2865 & 0.0102 \\
\hline 2 & 0.3538 & 0.0131 \\
\hline 3 & 0.3883 & 0.0144 \\
\hline 4 & 0.4097 & 0.0151 \\
\hline 5 & 0.4244 & 0.0154 \\
\hline
\end{tabular}

Table 12: Coverage, $\bar{R}=2$

\begin{tabular}{|c||c|c|c|c|}
\hline \multicolumn{1}{|c||}{$\underline{\mathrm{R}}$} & \multicolumn{2}{|c|}{1} & \multicolumn{2}{|c|}{2} \\
\hline Scenario & Cover & Welfare & Cover & Welfare \\
\hline \hline 1 & 0.6982 & 0.0562 & 0.7636 & 0.0791 \\
\hline 2 & 0.9829 & 0.0825 & 1.1204 & 0.1213 \\
\hline 3 & 1.1693 & 0.0972 & 1.3740 & 0.1472 \\
\hline 4 & 1.3060 & 0.1056 & 1.5726 & 0.1637 \\
\hline 5 & 1.4125 & 0.1103 & 1.7360 & 0.1742 \\
\hline
\end{tabular}

Table 13: Coverage, $\bar{R}=3$

\begin{tabular}{|c||c|c|c|c|c|c|}
\hline \multicolumn{1}{|c||}{$\underline{\mathrm{R}}$} & \multicolumn{2}{|c|}{1} & \multicolumn{2}{|c|}{2} & \multicolumn{2}{c|}{3} \\
\hline Scenario & Cover & Welfare & Cover & Welfare & Cover & Welfare \\
\hline \hline 1 & 1.0323 & 0.1481 & 1.1132 & 0.2319 & 1.1407 & 0.2822 \\
\hline 2 & 1.5700 & 0.2213 & 1.7583 & 0.3419 & 1.8239 & 0.4077 \\
\hline 3 & 1.9657 & 0.2615 & 2.2658 & 0.4022 & 2.3724 & 0.4744 \\
\hline 4 & 2.2824 & 0.2842 & 2.6944 & 0.4373 & 2.8434 & 0.5130 \\
\hline 5 & 2.5472 & 0.2967 & 3.0697 & 0.4583 & 3.2615 & 0.5364 \\
\hline
\end{tabular}



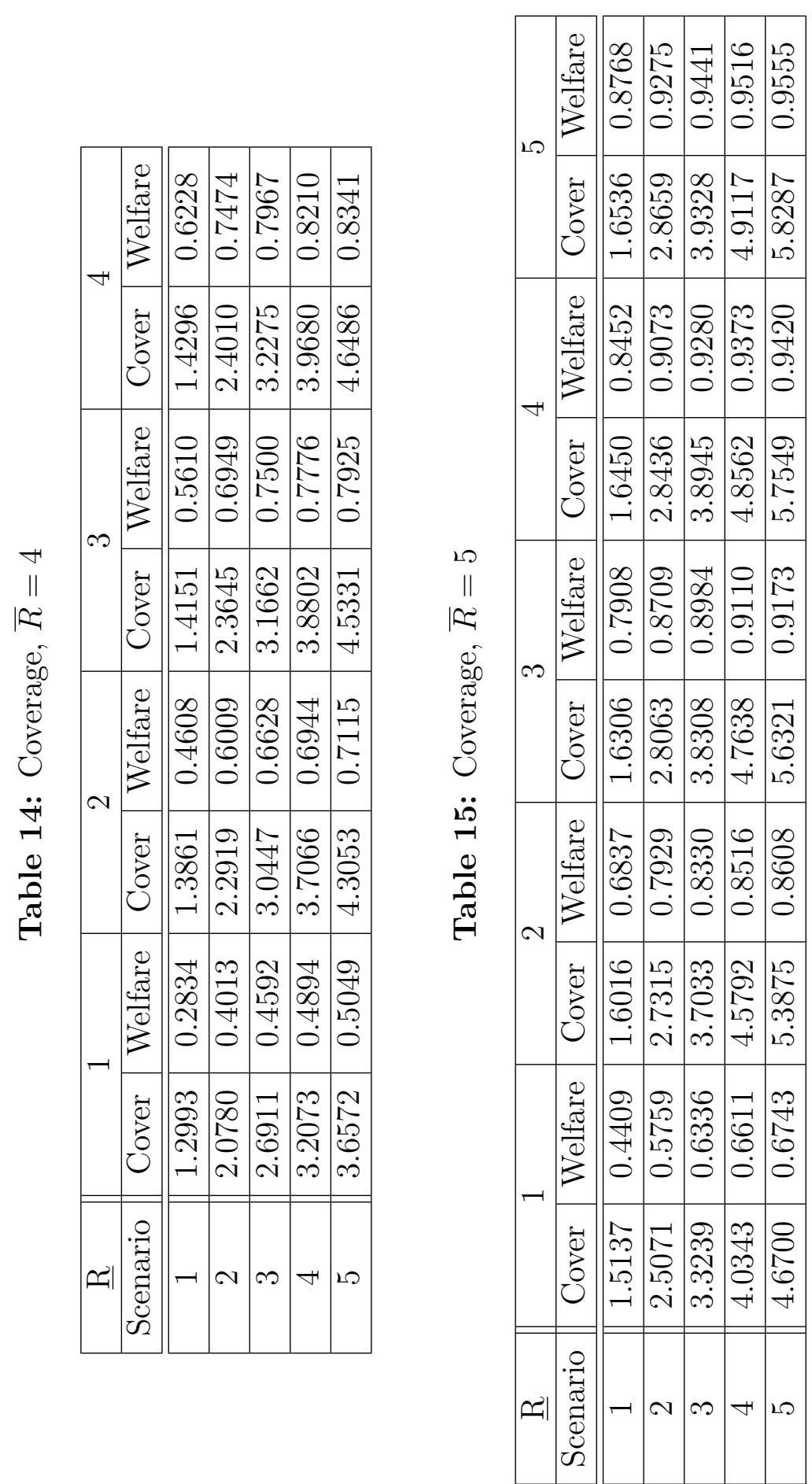
7.9.2 Optimal coverage and welfare gains with $\omega=0.975$

Table 16: Coverage, $\bar{R}=1$

\begin{tabular}{|c||c|c|}
\hline \multicolumn{1}{|c||}{$\underline{\mathrm{R}}$} & \multicolumn{2}{|c|}{1} \\
\hline Scenario & Cover & Welfare \\
\hline \hline 1 & 0.4132 & 0.0204 \\
\hline 2 & 0.5504 & 0.0288 \\
\hline 3 & 0.6342 & 0.0336 \\
\hline 4 & 0.6930 & 0.0366 \\
\hline 5 & 0.7192 & 0.0384 \\
\hline
\end{tabular}

Table 17: Coverage, $\bar{R}=2$

\begin{tabular}{|c||c|c|c|c|}
\hline \multicolumn{1}{|c||}{$\underline{\mathrm{R}}$} & \multicolumn{2}{|c|}{1} & \multicolumn{2}{|c|}{2} \\
\hline Scenario & Cover & Welfare & Cover & Welfare \\
\hline \hline 1 & 0.9278 & 0.1436 & 0.9469 & 0.1661 \\
\hline 2 & 1.4136 & 0.2203 & 1.4569 & 0.2545 \\
\hline 3 & 1.7824 & 0.2668 & 1.8509 & 0.3081 \\
\hline 4 & 2.0868 & 0.2962 & 2.1807 & 0.3424 \\
\hline 5 & 2.3484 & 0.3153 & 2.4677 & 0.3651 \\
\hline
\end{tabular}

Table 18: Coverage, $\bar{R}=3$

\begin{tabular}{|c||c|c|c|c|c|c|}
\hline \multicolumn{1}{|c||}{$\underline{\mathrm{R}}$} & \multicolumn{2}{|c|}{1} & \multicolumn{2}{|c|}{2} & \multicolumn{2}{|c|}{3} \\
\hline Scenario & Cover & Welfare & Cover & Welfare & Cover & Welfare \\
\hline \hline 1 & 1.3251 & 0.4429 & 1.3471 & 0.5303 & 1.3544 & 0.5669 \\
\hline 2 & 2.1618 & 0.5841 & 2.2156 & 0.6691 & 2.2337 & 0.7024 \\
\hline 3 & 2.8528 & 0.6484 & 2.9418 & 0.7284 & 2.9718 & 0.7594 \\
\hline 4 & 3.4589 & 0.6823 & 3.5852 & 0.7594 & 3.6277 & 0.7891 \\
\hline 5 & 4.0068 & 0.7014 & 4.1716 & 0.7769 & 4.2272 & 0.8062 \\
\hline
\end{tabular}



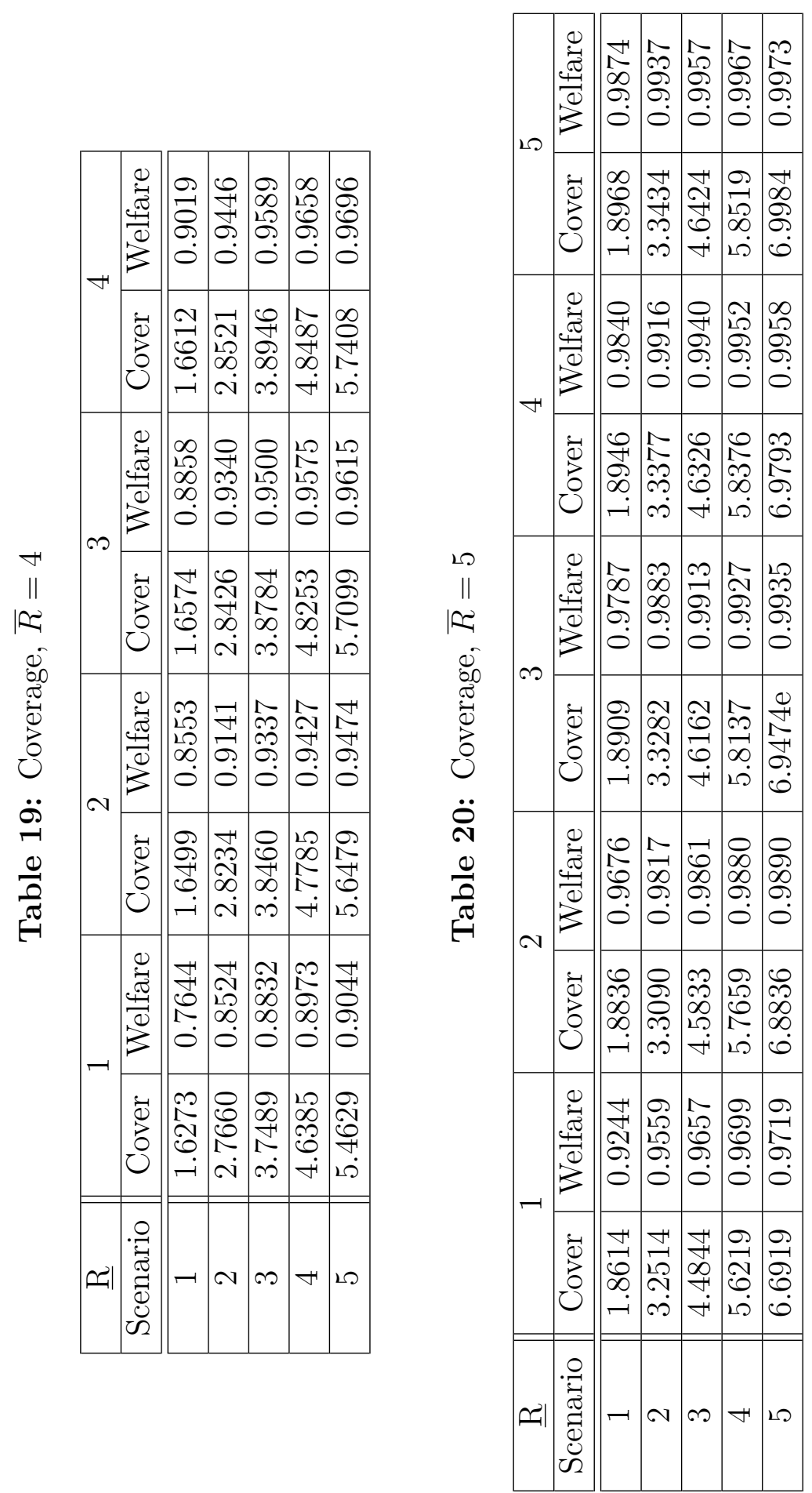


\section{Bibliography}

[1] Arrow, K. (1963). Uncertainty and the welfare economics of medical care. The American Economic Review, 53(5), 941-973.

[2] Barrieu, P. and Cummins, J. D. (2013). Innovations in insurance markets: hybrid and securitized risk-transfer solutions. In Handbook of Insurance (pp. 547-602). Springer New York.

[3] Barro, R. J. (2009). Rare disasters, asset prices, and welfare costs. The American Economic Review, 99(1), 243-264.

[4] Borensztein, E., Cavallo, E., and Jeanne, O. (2017). The welfare gains from macro-insurance against natural disasters. The Journal of Development Economics, Vol. 124, pp. 142-156.

[5] Braun, A. (2015). Pricing in the primary market for cat bonds: new empirical evidence. Journal of Risk and Insurance. Vol. 83, No. 4, pp. 811-847

[6] Cooter, R. and Ulen, T. (2004). Law and economics, 4th Ed. Addison Wesley.

[7] Dreicer M., Tort V., and Margerie H. (1995). The external costs of the fuel cycle: Implementation in France, CEPN report R-238.

[8] Eeckhoudt L., Schieber C. and Schneider T. (2000). Risk aversion and the external cost of a nuclear accident, Journal of Environmental Management, Vol. 58, pp. 109-117.

[9] Ehrlich, I., and Becker, G. S. (1972). Market insurance, self-insurance, and self-protection. Journal of political Economy, 80(4), 623-648.

[10] Farhi, E., and Gabaix, X. (2015). Rare disasters and exchange rates. The Quarterly Journal of Economics, 131(1), 1-52.

[11] Froot, K. A. (2001). The market for catastrophe risk: a clinical examination. Journal of Financial Economics, 60(2), 529-571.

[12] Gabaix, X. (2012). Variable rare disasters: an exactly solved framework for ten puzzles in macro-finance. The Quarterly Journal of Economics, qjs001. 
[13] Gignoux, J., Menéndez, M. (2016). Benefit in the wake of disaster: longrun effects of earthquakes on welfare in rural Indonesia. Journal of Development Economics, 118, 24-44.

[14] Gollier, C. (2003). To insure or not to insure?: an insurance puzzle. The Geneva Papers on Risk and Insurance Theory, 28(1), 5-24.

[15] Gollier, C. (2013), The economics of optimal insurance design, in Handbook of Insurance, G. Dionne (Ed), 2nd Edition, Springer, 107-122

[16] Gollier, C., and Schlesinger, H. (1996). Arrow's theorem on the optimality of deductibles: A stochastic dominance approach. Economic Theory, $7(2), 359-363$.

[17] Gourio, F. (2012). Disaster risk and business cycles. The American Economic Review, 102(6), 2734-2766.

[18] Ikefuji, M., Laeven, R. J., Magnus, J. R., and Muris, C. (2015). Expected utility and catastrophic consumption risk. Insurance: Mathematics and Economics, 64, 306-312.

[19] Jaffee, D., and Russell, T. (1997). Catastrophe insurance, capital markets, and uninsurable risks. The Journal of Risk and Insurance, 64(2), 205-230.

[20] IRSN (2013), Methodology applied by the IRSN to estimate the costs of a nuclear accident in France. Report PRP-CRI/SESUC/2013-00261.

[21] Lane, M. N. (2000). Pricing risk transfer transactions. Astin Bulletin, 30(2), 259-293.

[22] Lane, M. and Mahul, O. (2008). Catastrophe risk pricing: an empirical analysis. World Bank Policy Research Working Paper Series.

[23] Levy, H. (1994). Absolute and relative risk aversion: an experimental study. Journal of Risk and Uncertainty 8, 289-307.

[24] Louaas, A., and Picard, P. (2018). Optimal insurance coverage of low probability-high severity risks.hal-01924408

[25] Major, J. A. and Kreps, R. E. (2002). Catastrophe risk pricing in the traditional market. Alternative Risk Strategies, 201-222.

[26] Markandya, A. (1995). Externalities of fuel cycles ExternE project. Report economic valuation: an impact pathway approach. European commission DG XII. 
[27] Millner, A. (2013). On welfare frameworks and catastrophic climate risks. Journal of Environmental Economics and Management, 65(2), 310-325.

[28] Mossin, J. (1968). Aspects of rational insurance purchasing. The Journal of Political Economy, 553-568.

[29] NEA (2000). Methodologies for assessing the economic consequences of nuclear reactor Accidents, OECD Nuclear Energy Agency, Paris.

[30] Niehaus, G. (2002). The allocation of catastrophe risk. Journal of Banking and Finance, 26(2), 585-596.

[31] Perez, M. F., and Carayannopoulos, P. (2015). Diversification through catastrophe bonds: lessons from the subprime financial crisis. The Geneva Papers on Risk and Insurance-Issues and Practice, 40(2015), $1-28$.

[32] Quinet E., (2013). L'évaluation socioéconomique des investissements publics, Commissariat général à la stratégie et à la prospective, Paris

[33] Rabl, A., and Rabl, V. A. (2013). External costs of nuclear: Greater or less than the alternatives? Energy Policy, 57, 575-584

[34] Raviv, A. (1979). The design of an optimal insurance policy. The American Economic Review, 69(1), 84-96.

[35] Rangel, L. E., and Lévêque, F. (2014). How Fukushima Dai-ichi core meltdown changed the probability of nuclear accidents?. Safety Science, 64, 90-98.

[36] Rietz, T. (1988). The equity risk premium a solution. Journal of monetary Economics, 22(1), 117-131.

[37] Schneider, T. (1998). Integration of the indirect costs evaluation, CEPN Report No. 260.

[38] Schneider, Y and Zweifel, P. (2004). How much internalization of nuclear risk through liability insurance? Journal of Risk and Uncertainty, 29(3), 219-240.

[39] Strobl, E. (2012). The economic growth impact of natural disasters in developing countries: Evidence from hurricane strikes in the Central American and Caribbean regions. Journal of Development economics, 97(1), 130-141. 
[40] Shavell, S. (1987). Economic analysis of accident law. Harvard University Press.

[41] Szpiro, G. (1986). Measuring risk aversion: an alternative approach. The Review of Economics and Statistics, 68, 156-159.

[42] Viscusi, W. K., and Aldy, J. E. (2003). The value of a statistical life: a critical review of market estimates throughout the world. Journal of risk and uncertainty, 27(1), 5-76.

[43] Weitzman, M. L. (2009). On modeling and interpreting the economics of catastrophic climate change. The Review of Economics and Statistics, 91(1), 1-19.

[44] Zanjani, G. (2002). Pricing and capital allocation in catastrophe insurance. Journal of Financial Economics, 65(2), 283-305. 